\title{
OCUPACIONES HUMANAS EN LA MARGEN OCCIDENTAL DE PATAGONIA CENTRAL: EVENTOS DE POBLAMIENTO EN ALTO RÍO CISNES
}

\author{
CÉSAR MÉNDEZ M., OMAR REYES B.*, AMALIA NUEVO DELAUNAY"**, \\ VALENTINA TREJO V."***, RAMIRO BARBERENA ${ }^{* \ldots+*}$ Y HÉCTOR VELÁSQUEZ M."
}

\begin{abstract}
RESUMEN
Se presenta una síntesis de las investigaciones llevadas a cabo en el sitio El Chueco 1 (CIS 042). La localidad arqueológica corresponde a un punto de gran significancia para entender las dinámicas de poblamiento en una zona de ocupación marginal de Patagonia Central. La extensión temporal (11.500 a 2.570 años cal. AP.) y superposición de eventos discretos de ocupación hacen que el contexto excavado represente un buen medidor de los pulsos humanos regionales y su magnitud. En este trabajo se define la metodología de intervención del sitio y las líneas de análisis. Se caracteriza la estratigrafía, el conjunto de edades ${ }^{14} \mathrm{C}$ y los rasgos identificados. Asimismo, se presentan los resultados de los análisis de los conjuntos arqueológicos. Finalmente se discute y sintetizan las ocupaciones identificadas en el sitio y su importancia para la región.
\end{abstract}

PALABRAS CLAVE: ocupación de zonas marginales, eventos discretos, redundancia ocupacional, Patagonia Central.

\section{HUMAN OCCUPATIONS AT THE WESTERN MARGIN OF CENTRAL PATAGONIA: PEOPLING EVENTS AT UPPER CISNES BASIN}

\footnotetext{
ABSTRACT

We present a synthesis of the research conducted at El Chueco 1 site (CIS 042). The archaeological locality is a point of great significance for understanding the peopling dynamics in a marginally occupied area of Central Patagonia. The temporal extension (11.500 to 2.570 cal. years BP.) and discrete occupational event superposition make the excavated context a good measure for regional human pulses

Departamento de Antropología, Facultad de Ciencias Sociales, Universidad de Chile. C. Ignacio Carrera Pinto 1045, Nuñoa, Santiago, Chile.cmendezm@uchile.cl.

* Centro de Estudios del Hombre Austral, Instituto de la Patagonia, Universidad de Magallanes. Av. Bulnes 01890, Punta Arenas, Chile. omarreyesbaez@gmail.com.

*a Instituto Nacional de Antropología y Pensamiento Latinoamericano. 3 de Febrero 1378 (1426), Buenos Aires, Argentina. anuevodelaunay@gmail.com.

**** Martín Alonso Pinzón 6485, Las Condes, Santiago, Chile. valentinatrejovidal@gmail.com.

CONICET-IMHICIHU. Saavedra 15, $5^{\circ}$ piso (1083), Buenos Aires, Argentina. ramidus28@gmail.com.

L:s*:* La Tranquera 6329, San Joaquín, Santiago, Chile. hectorvelasquezcl@yahoo.es.
} 
and their magnitude. In this paper we define the site intervention methods and the analytical lines. We characterize the stratigraphy, the set of ${ }^{14} \mathrm{C}$ ages, and the identified features. We also present the results of the analyses of the archaeological assemblages. Finally, we discuss and synthesize the occupations recorded at the site and their regional significance.

KEY WORDS: occupation of marginal areas, discrete events, site redundancy, Central Patagonia.

\section{INTRODUCCIÓN}

La presencia humana en zonas marginales supone conductas discretas en la ocupación del espacio, lo que se traduce en señales arqueológicas bajas a muy bajas. Lejos de considerar esta escasez de registro arqueológico como un aspecto negativo, nos parece que localidades de uso recurrente con muy baja señal de ocupación otorgan una situación inmejorable para aislar lapsos de presencia humana. La riqueza de estos datos no reside en la cantidad de material, sino en su potencial como marcadores representativos de pulsos humanos en regiones amplias. En este sentido, eventos ocupacionales discretos con discontinuidades en el largo plazo (hiatos de miles de años) son informativos del uso humano de áreas marginales, distantes de los centros más poblados (Borrero 2004).

El sitio El Chueco 1 (CIS 042) corresponde a un reparo rocoso, localizado en un punto estratégico de alta visibilidad (Reyes et al. 2007, Méndez et al. 2009). Las características de sus ocupaciones pueden interpretarse como indicadoras del aprovechamiento de zonas marginales con evidencias de eventos muy discretos, el uso de tecnologías con diseños formales transportables y la explotación de fauna local durante la estación estival. Sus ocupaciones permiten evaluar la dinámica de presencia y ausencia humana en la región entre los 11.500 a 2.570 años cal. AP, por cuanto corresponde al único sitio estratificado detectado en el área del Alto río Cisnes.

Este trabajo se enmarca en un proyecto de investigación orientado a resolver el problema de las condicionantes del hallazgo de ocupaciones de la transición Pleistoceno/Holoceno en la estepa de Aisén y caracterizarlas a escala regional. Específicamente, sintetiza los datos e interpretaciones logrados a partir del estudio en profundidad del sitio arqueológico El Chueco 1. Los objetivos de este trabajo son dar a conocer las preguntas de investigación, los métodos implementados, los resultados del análisis de los conjuntos materiales, la interpretación del contexto y discutir las implicancias de los hallazgos a escala local y en su contexto regional. Para lo último, se compara el sitio El Chueco 1 con Baño Nuevo 1, el único otro sitio en la región de Aisén cuyas ocupaciones comparten similares rangos temporales a los aquí reportados. Finalmente, concluimos que la localidad es de central importancia para entender el poblamiento de los márgenes occidentales de Patagonia Central porque representa un buen medidor de la ocurrencia de pulsos humanos regionales y su magnitud.

\section{ÁREA DE ESTUDIO, AMBIENTE Y SÍNTESIS PALEOAMBIENTAL}

El sitio El Chueco 1 se ubica en la estepa norte de Aisén continental, en las cabeceras del valle del río Cisnes ( $44^{\circ} \mathrm{S}$; Figura 1$)$. Su emplazamiento corresponde a un afloramiento de origen volcánico de riodacita (Prieto et al. 1994), que se encuentra parcialmente cubierto por sedimento morrénico conformando un campo de drumlins (Ortega 2010). El área general de Alto Río Cisnes (850 a 950 msnm) se ubica en el sector de Relieves Planiformes Orientales de Aisén que corresponde a extensos planos depositacionales bordeados por lomajes suaves (SERPLAC 2005). En particular, el área constituye una gran cuenca lacustre periglaciar que estuvo activa hasta el Pleistoceno final, y de la cual quedan abundantes testigos geomorfológicos. Entre los últimos destacan al menos siete niveles de terrazas lacustres -paleocostas- (tres de mayor expresión), tres morrenas frontales, una zona de morrenas laterales indiferenciadas, tres campos de drumlins, un sector de remoción en masa y terrazas fluviales de origen reciente asociadas a los cauces activos (Ortega 2010). Actualmente, el área se caracteriza por un bajo nivel de pluviosidad producto del efecto sombra de lluvia, donde la cordillera de los Andes (al occidente) opera reteniendo gran parte de las precipitaciones acarreadas por el Cinturón 


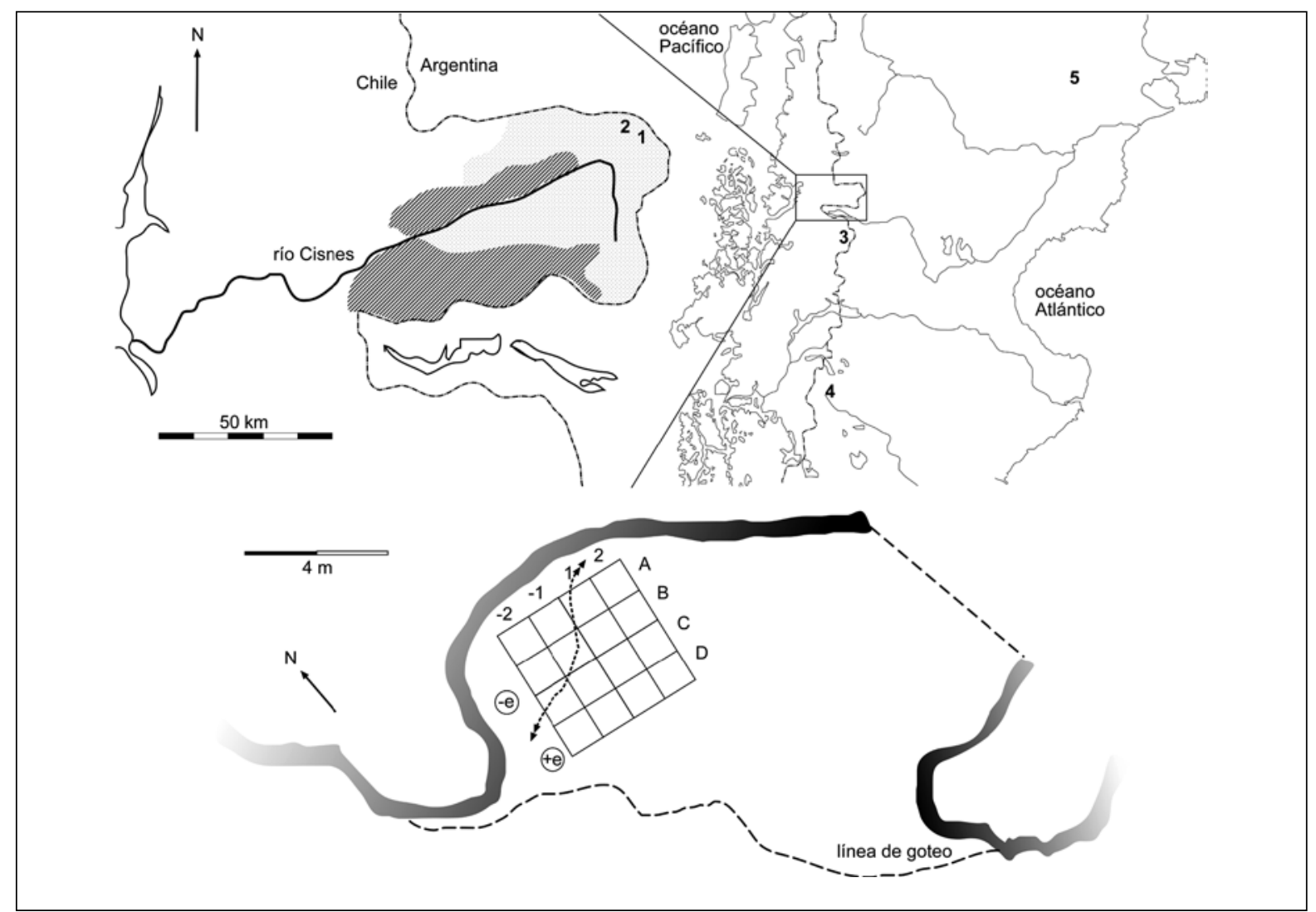

Fig. 1. Mapa mostrando la ubicación del área de estudio en Patagonia (derecha), una ampliación de la cuenca del Cisnes (izquierda) y planta del sitio CIS 042 (inferior); en el mapa sitios discutidos en el texto: 1) El Chueco (CIS 042), 2) El Shaman y 3) Baño Nuevo 1, fuentes de obsidiana 4) Pampa del Asador y 5) Telsen/Sierra Negra, en la ampliación: área color blanco: cordillera de Los Andes, área gris oscuro: Cordones Subandinos Orientales, área gris claro: Relieves Planiformes Orientales; en la planta: reticulado de excavación y áreas de alta (+e) y baja (-e) energia.

de Vientos del Oeste. Dicho mecanismo genera un piso vegetacional denominado como estepa mediterránea-templada de Festuca pallescens y Mulinum spinosum consecuente con un régimen de precipitaciones inferior a los $700 \mathrm{~mm}$ anuales (Luebert y Pliscoff 2006).

Investigaciones en la localidad Laguna El Shaman (Figura 1) han permitido reunir información de los cambios vegetacionales para los últimos 19.000 años cal. AP (Reyes et al. 2009). De manera sintética, una columna de polen fósil obtenida en este sitio muestra un contexto periglaciar en condiciones de baja humedad efectiva entre $19.000 \mathrm{y}$ 11.400 años cal. AP por el un dominio de especies de Poaceae y otros taxa de estepa arbustiva. En este rango, a los 14.700 años cal. AP se registra un incremento relativo de Nothofagus tipo dombeyi hasta los 13.300 años cal. AP donde incrementa porcentualmente Poaceae. A los 11.400 años cal. AP se registra un nuevo incremento en los porcentajes de Nothofagus tipo dombeyi configurándose en el área un paisaje transicional entre el bosque y la estepa. En adelante, los mayores porcentajes arbóreos son registrados para el lapso entre 8.200 y 3.000 años cal. AP, momento de las condiciones más húmedas durante el Holoceno. Al final de esta etapa decrece el indicador arbóreo, revelando un aumento de la estepa graminosa para luego, a partir de 1.500 años cal. AP, observar que el bosque se expandió nuevamente, manteniendo altos valores hasta tiempos históricos (Reyes et al. 2009). Las ocupaciones humanas del sitio El Chueco 1 son contemporáneas con gran parte de los cambios vegetacionales descritos. 


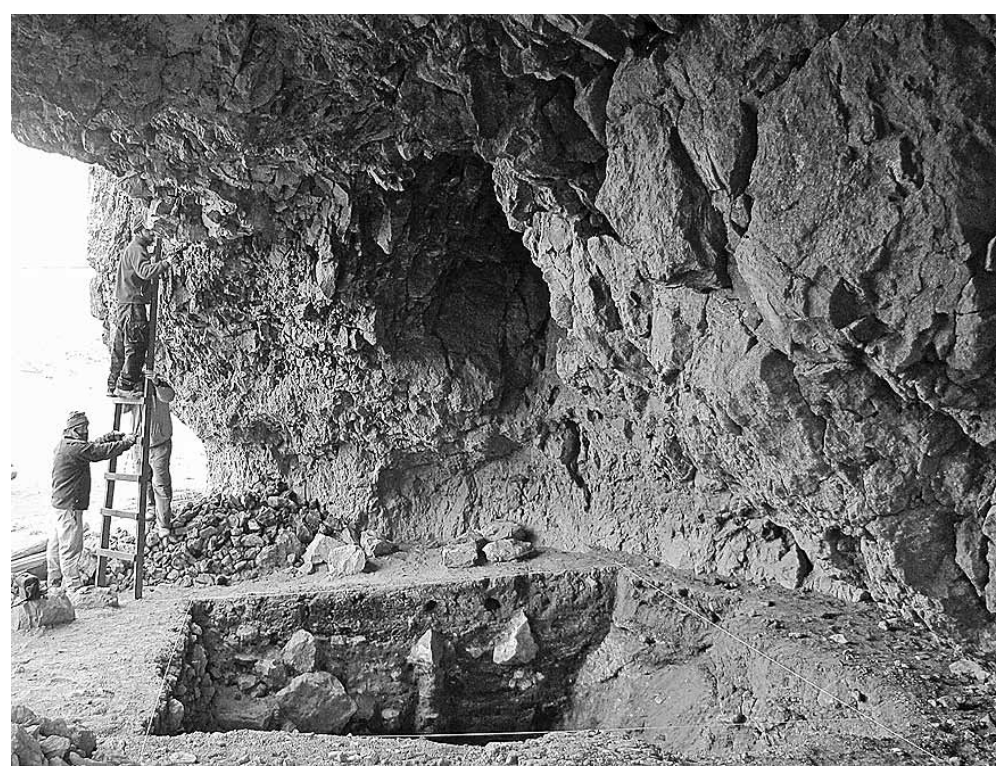

Fig. 2. Vista de la unidad de excavación al interior de CIS 042.

\section{METODOLOGÍA}

Este trabajo sintetiza resultados logrados anteriormente e incorpora los de la campaña de terreno del año 2009 donde se tuvo por objeto evaluar integralmente el sitio El Chueco 1. Se buscó entender la sucesión estratigráfica de los depósitos y las distribuciones indicativas de la acción humana. Para ello se excavó al interior del reparo rocoso, ampliando las unidades previas (Reyes et al. 2006, 2007). Se consideró una perspectiva estratigráfica y contextual en una área total de $16 \mathrm{~m}^{2}$ y un volumen aproximado de $\sim 32 \mathrm{~m}^{3}$ (Figura 2). La descripción de la sucesión estratigráfica buscó comprender los procesos de formación del sitio e identificar los agentes que incidieron en la depositación de los sedimentos. Esta evaluación integró la descripción lito-estratigrafica y análisis granulométricos (columna control en el perfil E de la excavación) y químicos (a partir de muestras de perfiles). La excavación incluyó individualización y posicionamiento tridimensional de piezas y rasgos. Se buscó recuperar partículas menores por medio de flotación de todos los rasgos, una columna de control (muestras de $1000 \mathrm{cc}$ ) y muestras de cada unidad $(250 \mathrm{cc})$ de los niveles inferiores. Se llevó a cabo una recuperación sistemática de las evidencias de carbón en rasgos y fuera de ellos. En el talud de la cueva se excavó una unidad de control de 5 $\mathrm{m}^{2}$ llegando a una profundidad media de $220 \mathrm{~cm}$, donde también se realizó una columna de flotación (muestras de $2250 \mathrm{cc}$ ).

Los métodos analíticos en laboratorio incluyeron el uso de fechados ${ }^{14} \mathrm{C}$ AMS para establecer ritmos de depositación (modelo de edad/profundidad) y posicionar temporalmente las ocupaciones humanas. Para ello se corrigieron los resultados convirtiendo las edades a años calendario antes del presente (cal. AP.) con el programa OxCal 4.01 (Bronk Ramsey 2009), con la curva ShCal04 para las edades $<10.000$ años cal. AP y la curva IntCal09 para las edades $>10.000$ años cal. AP. El material lítico fue analizado siguiendo criterios tecno-tipológicos para evaluar el índice de completitud, las clases instrumentales de acuerdo a criterios morfo-funcionales (Jackson 2002), las materias primas y su calidad para la talla (Aragón y Franco 1997) y dibujos técnicos (Inizan et al. 2004). Análisis de muestras de obsidiana fueron llevados a cabo con la técnica ICP-MS en la University of Colorado. Para el estudio del material faunístico, la unidad mínima de análisis fue el espécimen (Mengoni 1999). Inicialmente se recuperó información biológica de la muestra orientada a la determinación taxonómica, anatómica y edad de los especímenes analizados (Reitz y Wing 1999). Posteriormente, se aplicaron medidas de cuantificación para determinar abundancia taxonómica (NISP y MNI; Grayson 1984, Klein y Cruz-Uribe 1984) y anatómica (MNE y MAU; Binford 1984), se analizaron las huellas producto de 
Tabla 1. Resultados del análisis de granulometría de sedimentos de CIS 042, muestras (150 gr).

Las muestras fueron obtenidas de la columna en la unidad c(2), salvo *unidades a-c(-2) y * unidad b(-

2). En adelante UEST: unidad estratigráfica. (Laboratorio de Análisis, CNCR, DIBAM).

\begin{tabular}{|c|c|c|c|c|c|c|}
\hline UEST & Nivel $(\mathrm{cm})$ & $\%$ arena & $\%$ limo & $\%$ arcilla & $\%$ del total & Clase textural \\
\hline \multirow{2}{*}{1} & 0 a 10 & 9,9 & 31,2 & 56,8 & 97,9 & Arcilla \\
\cline { 2 - 6 } & 10 a 20 & 1,5 & 35,9 & 60,2 & 97,6 & Arcilla \\
\hline \multirow{3}{*}{3} & 30 a 40 & 2,4 & 39,4 & 50,1 & 98,2 & Arcilla \\
\cline { 2 - 6 } & 40 a 50 & 8,9 & 38,0 & 50,8 & 97,7 & Arcilla \\
\hline \multirow{4}{*}{4} & 70 a 80 & 2,1 & 40,2 & 55,2 & 97,5 & Limo-arcilloso \\
\cline { 2 - 7 } & 90 a 100 & 6,2 & 38,5 & 54,1 & 98,8 & Arcilla \\
\cline { 2 - 7 } & 110 a 120 & 0,3 & 42,5 & 55,6 & 98,4 & Limo-arcilloso \\
\cline { 2 - 7 } & 130 a 140 & 0,8 & 32,6 & 65,7 & 99,1 & Arcilla \\
\hline \multirow{3}{*}{5} & 160 a 170 & 9,8 & 39,4 & 50,1 & 99,3 & Arcilla \\
\hline \multirow{3}{*}{5} & 170 a 180 & 7,9 & 35,4 & 55,3 & 98,6 & Arcilla \\
& 190 a 200 & 8,3 & 38,5 & 52,1 & 98,9 & Arcilla \\
\cline { 2 - 7 } & 200 a 210 & 1,8 & 35,4 & 60,3 & 97,5 & Arcilla \\
\hline \multirow{2}{*}{6} & 220 a 230 & 7,1 & 33,2 & 58,4 & 98,7 & Arcilla \\
\hline
\end{tabular}

acción humana (Binford 1981) y se diagnosticaron los factores tafonómicos que pudieron incidir en el conjunto (Behrensmeyer 1978, Lyman 1994). Para el análisis de los carporestos, luego de segregarse la fracción pesada de la liviana en las muestras de flotación (Greig 1989), se utilizó lupa binocular (aumentos de 15X a 20X) para su identificación taxonómica, la que se basó en colecciones de referencia y bibliografía especializada (Belmar 2010).

\section{ESTRATIGRAFÍA DE LOS DEPÓSITOS Y MODELO DE EDAD/PROFUNDIDAD}

Los depósitos al interior de la cueva están compuestos de arcillas (y en menor proporción limos) de origen exógeno (Tabla 1) y brecha endógena de clastos angulosos, más grandes hacia el interior de la cueva (>60 cm, Ortega 2010). Hacia el exterior de la cueva hay mayor densidad de clastos entre 5 y 20 $\mathrm{cm}$ producto de la mayor meteorización física (lluvia, nieve, oscilación térmica). En una primera etapa, sobre la base de excavaciones restringidas a $4 \mathrm{~m}^{2}$, se había descrito que por el colapso de partículas rocosas del techo y paredes... Las condiciones de depositación no admiten el reconocimiento de unidades estratigráficas discretas (Reyes et al. 2007:111). Con este problema en mente se buscó ampliar las excavaciones a fin de lograr una lectura más representativa de la sucesión estratigráfica. Así, se identificaron sectores donde la acción conjunta entre el colapso de rocas del techo y el arrastre por la pendiente (hacia el SE) produjo áreas colmatadas de clastos en contraposición a sectores menos afectos a esta dinámica (NO) donde sedimentos más finos y la acumulación de lluvia o nieve probablemente favorecieron la formación ocasional e incipiente de suelos. Los mecanismos descritos se muestran claramente en los perfiles y fueron definidos como áreas de alta y baja energía, respectivamente (Figura 1). Los perfiles Sur y Este representan áreas de alta energía, mientras que el perfil Oeste evidencia una mayor proporción de área de baja energía (Figura $3)^{1}$. Las unidades estratigráficas, no obstante, fueron descritas uniformemente para toda la excavación, contemplando la diferencial incorporación de clastos de acuerdo a las áreas.

La secuencia del sitio se inicia con una unidad estratigráfica superficial (UE1) correspondiente a una cubierta semi-uniforme de guano de oveja con baja proporción de clastos y límite inferior neto. La unidad estratigráfica 2 (UE2) se representa sólo en el perfil Oeste y corresponde a un sector donde se pudo identificar bioturbación animal relativamente reciente (túneles bien delimitados), con una matriz limosa, color café claro y alto contenido de guano. La unidad estratigráfica 3 (matriz sostén) se expresa en toda el área excavada y posee una matriz arcillosa, color café oscuro, con clastos pequeños y en muy baja abundancia en el área de baja energía y

1 El continuo colapso de sedimentos durante la excavación no permitió describir el perfil Norte. 


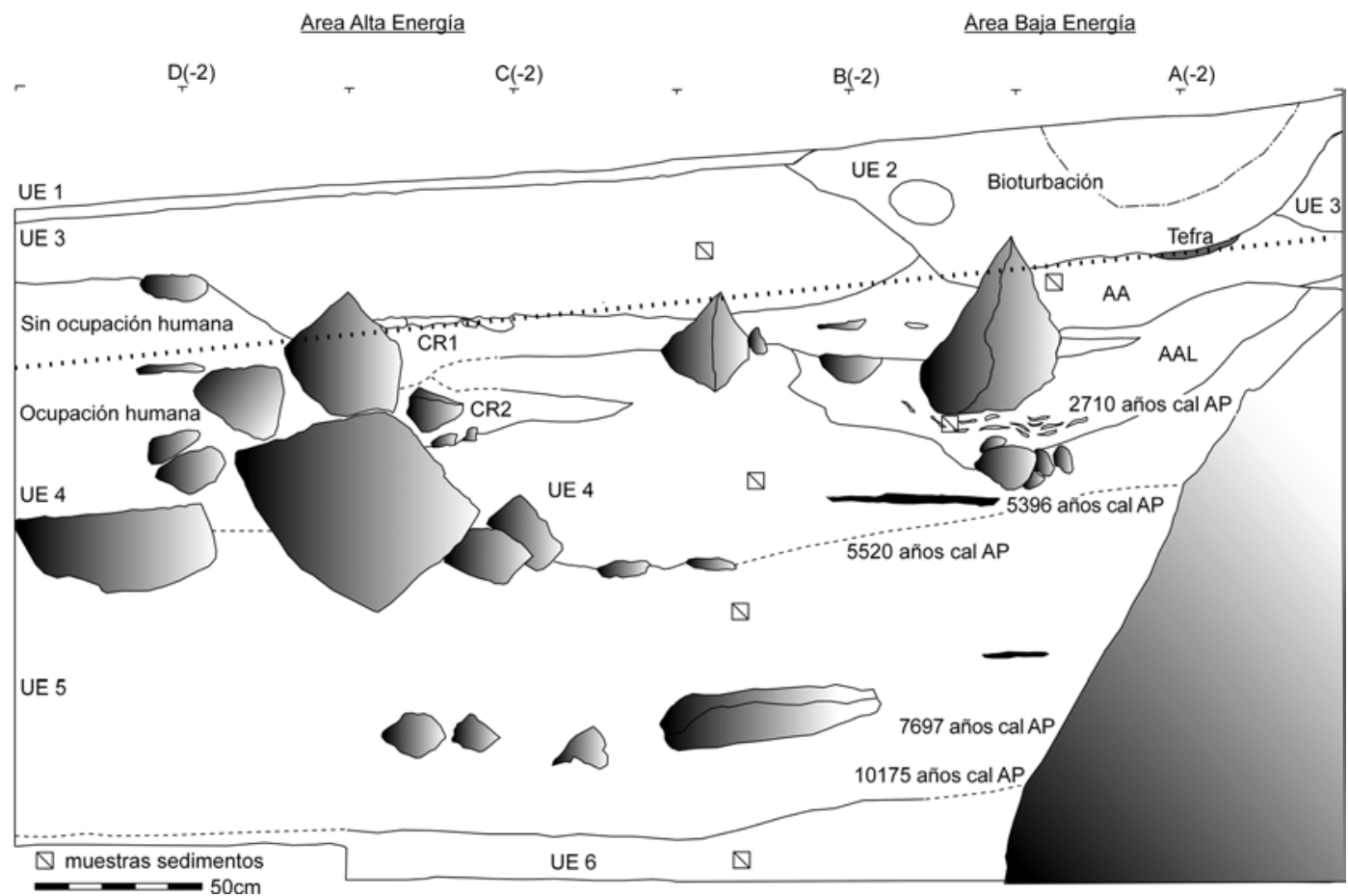

Fig. 3. Estratigrafía del perfil Oeste de la unidad de excavación de CIS 042, mostrando unidades estratigráficas, proyección de algunas edades ${ }^{14} \mathrm{C}$ (medianas en años cal. AP.) y rasgos relevados en el perfil; CR: concentración de roedores (regurgitado), AA: arcillas amarillas, AAL: arcillas amarillas laminadas, en negro: fogones.

abundantes clastos, que ocasionalmente se expresan como flujos (clasto sostén), en las áreas de alta energía (perfiles S y E). La unidad posee abundante materia orgánica (Tabla 2) y un límite inferior neto. La unidad estratigráfica 4 (UE4), también se presenta en toda la excavación, posee matriz arcillosa y limo-arcillosa, con un color café oscuro, abundante materia orgánica, clastos poco abundantes y su límite inferior es difuso. La presencia de raicillas acusa probables procesos pedogenéticos de tipo cumúlico incipientes. Sólo en los perfiles sur y este se observa ocasionalmente una matriz de tipo clasto sostén. En el perfil oeste la unidad contiene: estructuras de abundante acumulación de restos óseos de roedores producto del regurgitado de aves; estructuras de arcillas amarillas (ocasionalmente laminadas) probablemente producto de la descomposición de la roca en sectores de acumulación de humedad y cenizas de origen volcánico, color gris oscuro. La unidad estratigráfica 5-UE5(matriz sostén) presenta una matriz arcillosa, color café muy oscuro, con baja abundancia de clastos, posibles indicadores de pedogénesis y límite inferior difuso. La unidad estratigráfica 6 -UE6- (matriz sostén) sólo se expresa en el perfil oeste (sector más profundo de la excavación) y corresponde a arcillas color café-rojizo claro, matriz muy orgánica, muy poca cantidad de clastos, está desprovista de carbón y su límite inferior es desconocido. Los depósitos antrópicos se desarrollan entre el límite inferior de la unidad estratigráfica 3 y el límite inferior de la unidad estratigráfica 5, donde se hallan representados 9000 años de ocupaciones humanas.

Las excavaciones al exterior del reparo revelaron una sucesión estratigráfica significativamente diferente (Ortega 2010). En los primeros $80 \mathrm{~cm}$ (unidad estratigráfica 1) se observa el nivel de suelo actual, compuesto por 70\% de limo-arcilla y 30\% de arena, color café oscuro, escasos clastos de brecha y abundantes raicillas verticales en todo el estrato. La unidad estratigráfica $2(40 \mathrm{~cm})$, color gris-café claro, se compone de un $80 \%$ de limo-arcilla y un $20 \%$ de arena. Un análisis ${ }^{14} \mathrm{C}$ sobre material orgánico arrojó altos porcentajes de carbón moderno (103,46 $\pm 0,29$; UGAMS 5964). La unidad estratigráfica 3 (con límite inferior desconocido) corresponde a un estrato de toba blanca, matriz soportada $(60 \%$ 
Tabla 2. Síntesis de los análisis químicos en sedimentos de CIS 042 interior

(Laboratorio de Análisis, CNCR, DIBAM) y valores promediados.

\begin{tabular}{|c|c|c|c|c|}
\hline UEST & Perfil & $\mathrm{pH}$ & Materia orgánica (\%) & mg P/kg de suelo \\
\hline 1 & $E$ & 5,38 & 14,06 & 210,16 \\
\hline \multirow{4}{*}{3} & $\mathrm{~S}$ & 6,38 & 31,96 & 370,4 \\
\hline & $E$ & 4,82 & 29,35 & 308,88 \\
\hline & $\mathrm{W}$ & 5,03 & 39,57 & 281,2 \\
\hline & $X(d s)$ & $5,4(0,69)$ & $28,74(10,7)$ & $292,66(66,44)$ \\
\hline \multirow{7}{*}{4} & $\mathrm{~N}$ & 4,96 & 4,87 & 372,56 \\
\hline & $\mathrm{S}$ & 5,98 & 16,06 & 316,32 \\
\hline & $E$ & 4,20 & 7,52 & 5,664 \\
\hline & W & 3,73 & 21,23 & 311,36 \\
\hline & W & 4,81 & 28,04 & 365,04 \\
\hline & W & 3,44 & 23,26 & 308,88 \\
\hline & $X(d s)$ & $4,52(0,93)$ & $16,83(9,13)$ & $279,97(137,26)$ \\
\hline \multirow{4}{*}{5} & $\mathrm{~S}$ & 5,14 & 8,19 & 102,64 \\
\hline & $\mathrm{E}$ & 3,94 & 6,14 & 6,912 \\
\hline & $\mathrm{W}$ & 3,34 & 17,87 & 156,48 \\
\hline & $X(d s)$ & $4,14(0,92)$ & $10,73(6,26)$ & $88,68(75,76)$ \\
\hline 6 & W & 3,31 & 4,19 & 129,04 \\
\hline
\end{tabular}

matriz de ceniza blanca muy fina, $40 \%$ clastos), que presenta un 3\% de vidrio volcánico cuyo análisis geoquímico la asignó a la obsidiana variedad Cisnes (Méndez et al. 2008/9). La sucesión estratigráfica en el talud de El Chueco se caracteriza por una total ausencia de material cultural (excavación y muestra de control de flotación).

A fin de entender la dimensión cronológica del sitio se seleccionaron 14 muestras para fechar: considerando rasgos (principalmente estructuras de combustión), espículas de carbón (en ausencia de rasgos), acumulaciones vegetales y huesos animales
(Tabla 3). Se privilegió la selección de rasgos que mostraran integridad en el área de baja energía (cercanas al perfil oeste) a fin de limitar el potencial desplazamiento en el sector con dinámicas de formación más agresivas. A partir de una selección de las edades ${ }^{14} \mathrm{C}$ se llevó a cabo un modelo de edad/ profundidad del sitio (Figura 4) con el propósito de entender la cronología de la sucesión estratigráfica, identificar los ritmos de depositación y asignar los conjuntos materiales a bloques temporales. Para este modelo se excluyeron dos edades que mostraron haberse desplazado verticalmente (Tabla 3), un resto

Tabla 3. Síntesis de las edades ${ }^{14} \mathrm{C}$ AMS obtenidas en CIS 042 y valores calibrados, * muestras desplazadas estratigráficamente, ${ }^{£}$ en Reyes et al. 2007, B: Beta Analityc Inc. y U: UGAMS, CAIS lab. University of Georgia. UE: Unidad Estratigráfica.

\begin{tabular}{|c|c|c|c|c|c|c|}
\hline Muestra & UE & Cód. lab. & ${ }^{14} \mathrm{C}$ en años AP. & $\delta^{13} \mathrm{C}, \% 0$ & Rango $2 \sigma$ años cal. AP. & Mediana \\
\hline rasgo c (fogón) & & B-227701 & $5.950 \pm 50$ & -25.1 & $6.902-6.665$ & 6.780 \\
\hline rasgo d (fogón) & 5 & B-227702 & $8.250 \pm 60$ & -26.5 & $9.417-9.032$ & 9.228 \\
\hline rasgo i (fogón) & 4 (proy) & U-5839 & $2.550 \pm 25$ & -28.0 & $2.749-2.505$ & 2.710 \\
\hline rasgo k (fogón) & 4 & U-6108 & $4.690 \pm 30$ & -23.0 & $5.577-5.320$ & 5.396 \\
\hline rasgo m (fogón) & 5 (techo proy) & U-5840 & $4.770 \pm 25$ & -21.4 & $5.588-5.469$ & 5.520 \\
\hline rasgo n (fogón) & 5 & U-6109 & $6.070 \pm 30$ & -24.9 & $7.141-6.800$ & 6.928 \\
\hline rasgo q (Festuca) & 5 & U-5841 & $6.870 \pm 30$ & -27.1 & $7.788-7.625$ & 7.697 \\
\hline rasgo t (cenicero) & 5 (base) & U-5842 & $8.970 \pm 30$ & -17.7 & $10.228-9.933$ & 10.175 \\
\hline rasgo u (conc. carbón) & 5 & U-6110 & $8.830 \pm 30$ & -25.4 & $10.150-9.708$ & 9.890 \\
\hline rasgo w (m. orgánica) & $6^{*}$ & U-5843 & $8.830 \pm 30$ & -23.1 & $10.150-9.708$ & 9.890 \\
\hline espícula carbón & 4 & B-214639 & $2.480 \pm 40$ & -25.9 & $2.719-2.365$ & 2.567 \\
\hline espícula carbón & 5 & B-227703 & $10.010 \pm 60$ & -25.7 & $11.756-11.266$ & 11.502 \\
\hline hueso L. guanicoe & $4^{*}$ & U-6107 & $110 \pm 25$ & -20.1 & $268-16$ & 112 \\
\hline hueso L. guanicoe & 4 (¿base?) & U-6106 & $2.990 \pm 30$ & -20.2 & $3.320-3.075$ & 3.182 \\
\hline
\end{tabular}




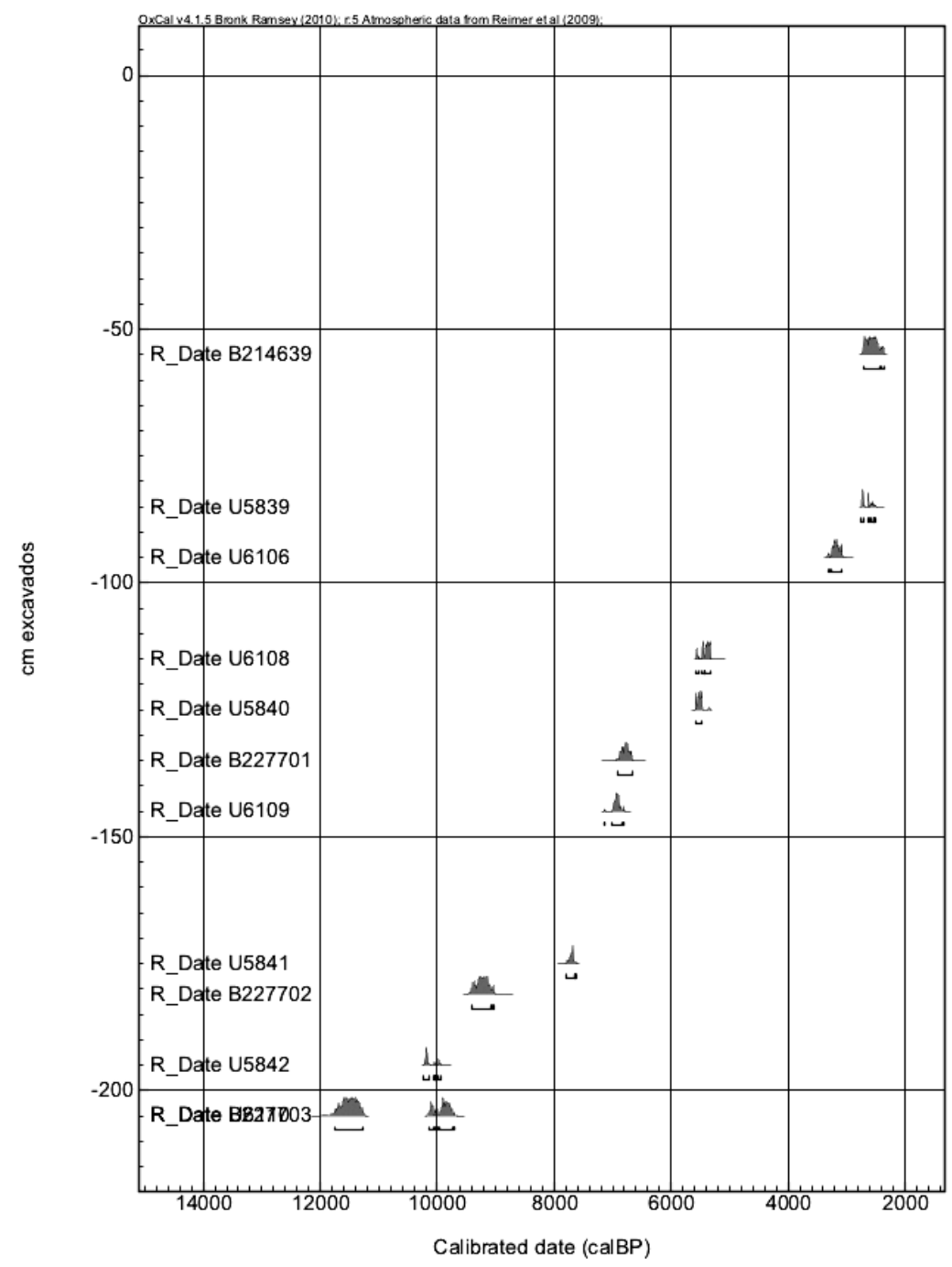

Fig. 4. Modelo edad/profundidad de CIS 042, excluyendo edades ${ }^{14} \mathrm{C}$ desplazadas.

óseo en el área de alta energía y un fragmento de materia orgánica en la unidad estratigráfica 6 (estéril), posiblemente relocalizada por el colapso de rocas. Algunas observaciones son necesarias: 1) el modelo muestra una clara sucesión estratigráfica ordenada como había sido previamente sugerido (Reyes et al. 2007), aún cuando debemos mantener cautela por la gran incorporación de clastos al depósito. 2) La edad más antigua (11.500 años cal. AP) se observa a la misma profundidad que la siguiente, debido a que la primera proviene del sector noreste de la excavación (efecto pendiente), único lugar donde se detectó este discreto evento humano. 3) Se observó una tasa de sedimentación relativamente constante para los niveles bajo los 2.710 años cal. AP, donde sucede una fuerte inflexión al alza. 4) La aceleración en la tasa de sedimentación puede deberse a una incorporación relativamente reciente y agresiva de partículas, como lo sugiere la edad ${ }^{14} \mathrm{C}$ en hueso de Lama guanicoe de 112 años cal. AP desplazado verticalmente y la presencia de restos de Ovis aries hasta los $80 \mathrm{~cm}$ de profundidad, aunque con un decrecimiento sostenido desde los $50 \mathrm{~cm}$ en adelante (Trejo y Velásquez 2011). 5) Esta segunda tasa de sedimentación coincide con la unidad estratigráfica 3.

Como síntesis, la información estratigráfica y los valores calibrados (medianas) de las edades ${ }^{14} \mathrm{C}$ han permitido definir seis bloques temporales que 
enmarcan las ocupaciones detectadas: 1) un discreto evento ocupacional hacia los 11.500 años cal. AP., 2) dos bloques durante el Holoceno temprano (1 y 2), el primero entre los 10.180 y 9.890 años cal. AP y el segundo datado hacia los 9.230 años cal. AP y con una fecha mínima cerca de los 7.700 años cal. $\mathrm{AP}, 3)$ dos bloques durante el Holoceno medio (1 y 2), el primero entre los 6.930 y 6.780 años cal. AP y el segundo entre los 5.520 y 5.400 años cal. AP y 4) un lapso de ocupaciones reiteradas indiferencias en el Holoceno tardío entre los 3.180 y 2.570 años cal. AP. Estos rangos serán la guía para ordenar la exposición de los resultados analíticos de los conjuntos depositados.

\section{DISTRIBUCIÓN DE RASGOS Y ORDENAMIENTO DEL ESPACIO INTERNO}

Los reparos rocosos poseen características intrínsecas (estructurales) que moldean la ocupación humana en su interior (Jackson 2007). Pensamos que la disposición de rasgos dentro de los reparos constituye un buen indicador para entender el ordenamiento interno de las actividades (Figuerero 2000,
Galanidou 2000). En el caso del sitio El Chueco 1, el análisis de la disposición de las estructuras de combustión en consideración con las propiedades estructurales del reparo, presenta una oportunidad para observar cambios y continuidades en los modos de ocupación de un mismo espacio a lo largo de varias ocupaciones superpuestas. En este sentido, esperamos que los rasgos diagnósticos de actividades se ubiquen más cercanos a los sectores reparados (i.e. fondo y paredes) y que las áreas de descarte de basuras se localicen en las vías de evacuación y/o tránsito y hacia las afueras del reparo. La información referente a los rasgos discretos identificados y su ubicación en la excavación se encuentra en la Tabla 4. Estos datos permiten visualizar que, de los rasgos asociados a actividades de combustión (concentraciones de carbón, fogones y ceniceros; $\mathrm{N}=19$ ), la gran mayoría $(78,9 \%)$ se encuentran ubicados en las unidades próximas a las paredes y otros sectores reparados [unidades $\mathrm{a}(2), \mathrm{a}(1), \mathrm{a}(-1), \mathrm{a}(-2), \mathrm{b}(-1), \mathrm{b}(-2)$; Figura 1], mientras que pocos (15,8\%) se emplazan en sectores de reparo medio [unidad c(2) o límite $\mathrm{b}(-2) / \mathrm{c}(-2)]$ y sólo un caso se identificó directamente en un área de alta exposición. Por su parte, una

Tabla 4. Resumen de rasgos identificados en CIS 042 interior y edades 14C AMS directas.

\begin{tabular}{|c|c|c|c|c|}
\hline Rasgos & Unidad excavación & Profundidad $(\mathrm{cm})$ & Descripción & Mediana \\
\hline rasgo a & a1 & 60 a 70 & Fogón & - \\
\hline rasgo b & a1 & 70 a 80 & Fogón & - \\
\hline rasgo c & $\mathrm{a} 2$ & 130 a 140 & Fogón & 6.780 años cal. AP \\
\hline rasgo d & a1 & 181 a 182 & Fogón & 9.228 años cal. AP \\
\hline rasgo e & $\mathrm{c} 2$ & 50 a 60 & Fogón & - \\
\hline rasgo $\mathrm{f}$ & $c(-2)$ & 60 a 70 & Fogón & - \\
\hline rasgo $\mathrm{g}$ & $c(-1), c(-2)$ & 50 a 70 & Concentración de roedores & - \\
\hline rasgo $\mathrm{h}$ & $\mathrm{d}(-1)$ & 70 a 80 & Columna guanaco articulada & - \\
\hline rasgo i & $a(-1), a(-2), b(-1), b(-2)$ & 80 a 90 & Fogón con rubefacto & 2.710 años cal. AP \\
\hline rasgo j & $\mathrm{c} 2$ & 80 a 90 & Concentración de carbón & - \\
\hline rasgo $\mathrm{k}$ & $b(-2), c(-2)$ & 110 a 120 & Fogón & 5.396 años cal. AP \\
\hline rasgo 1 & $\mathrm{a}(-1)$ & 120 a 130 & Fogón & - \\
\hline rasgo $\mathrm{m}$ & $\mathrm{b}(-2)$ & 120 a 130 & Fogón con rubefacto & 5.520 años cal. AP \\
\hline rasgo $\mathrm{n}$ & $\mathrm{a}(-1)$ & 140 a 150 & Fogón & 6.928 años cal. AP \\
\hline rasgo o & $a(-2), b(-2)$ & 150 a 160 & Micro concentración de carbón & - \\
\hline rasgo $\mathrm{p}$ & $\mathrm{b}(-1)$ & 160 a 170 & Micro concentración de carbón & - \\
\hline rasgo $\mathrm{q}$ & $\mathrm{a}(-2)$ & 170 a 180 & Festuca preservado entre rocas & 7.697 años cal. AP \\
\hline rasgo $r$ & $\mathrm{~b}(-2)$ & 180 a 190 & Fogón & - \\
\hline rasgo s & $\mathrm{a}(-1)$ & 190 a 200 & Concentración de carbón & - \\
\hline rasgo $\mathrm{t}$ & $\mathrm{a}(-1)$ & 190 a 200 & Cenicero y carbones grandes & 10.175 años cal. AP \\
\hline rasgo $\mathrm{u}$ & $\mathrm{a} 1, \mathrm{a}(-1)$ & 200 a 210 & Concentración de carbón & 9.890 años cal. AP \\
\hline rasgo $\mathrm{v}$ & $\mathrm{a}(-1)$ & 200 a 210 & concentración de carbón & - \\
\hline rasgo $\mathrm{w}$ & $\mathrm{a}(-2)$ & 210 a 220 & Materia orgánica (¿Festuca?) & 9.890 años cal. AP \\
\hline
\end{tabular}


cuantificación del NISP de los restos óseos de $L$. guanicoe ${ }^{2}$ permite observar que éstos se ubican en el sector menos reparado [unidades $c(2), c(1), c(-1)$, $c(-2), d(2), d(1), d(-1), d(-2)$, en un $100 \%$ para los dos bloques del Holoceno medio y en un 95\% durante el Holoceno tardío (Trejo y Velásquez 2011). La preservación diferencial no explica estos patrones, ya que en el área de alta energía hay tanto unidades sin restos óseos [a(1), a(2), b(1), b(2)], como unidades -en la mitad sur de la excavación- que concentran la gran mayoría. Por su parte, si bien en el área de baja energía no se registró una gran frecuencia de restos óseos de mamíferos de mediano y gran tamaño, los restos de roedores abundan en la unidad estratigráfica 4 y en muy buena condición.

2 Principal taxa representado y único con indicadores más claros de consumo humano. Otras basuras como los desechos de talla son sumamente infrecuentes en el contexto como para realizar una cuantificación en el espacio excavado.
Pensamos que, al igual que las distribuciones de rasgos de combustión, la disposición de los restos óseos no es azarosa, sino que se encuentra pautada. Esta recurrencia es altamente significativa por cuanto muestra similares criterios de ocupación del espacio a lo largo del tiempo. Los rasgos de combustión se distribuyen para el lapso entre 10.180 y 2.570 años cal. AP y los huesos sólo fueron identificados para los niveles con fechas posteriores a los 6.930 años cal. AP. Proponemos que este singular ordenamiento es especialmente visible dada la baja intensidad de las ocupaciones humanas en el sitio. Incluso, es más evidente para el bloque entre los 3.180 a 2.570 años cal. AP, donde se observa que los fogones se disponen hacia el sector norte (más reparo), mientras que los restos óseos se descartan hacia la entrada de la cueva (Figura 5).

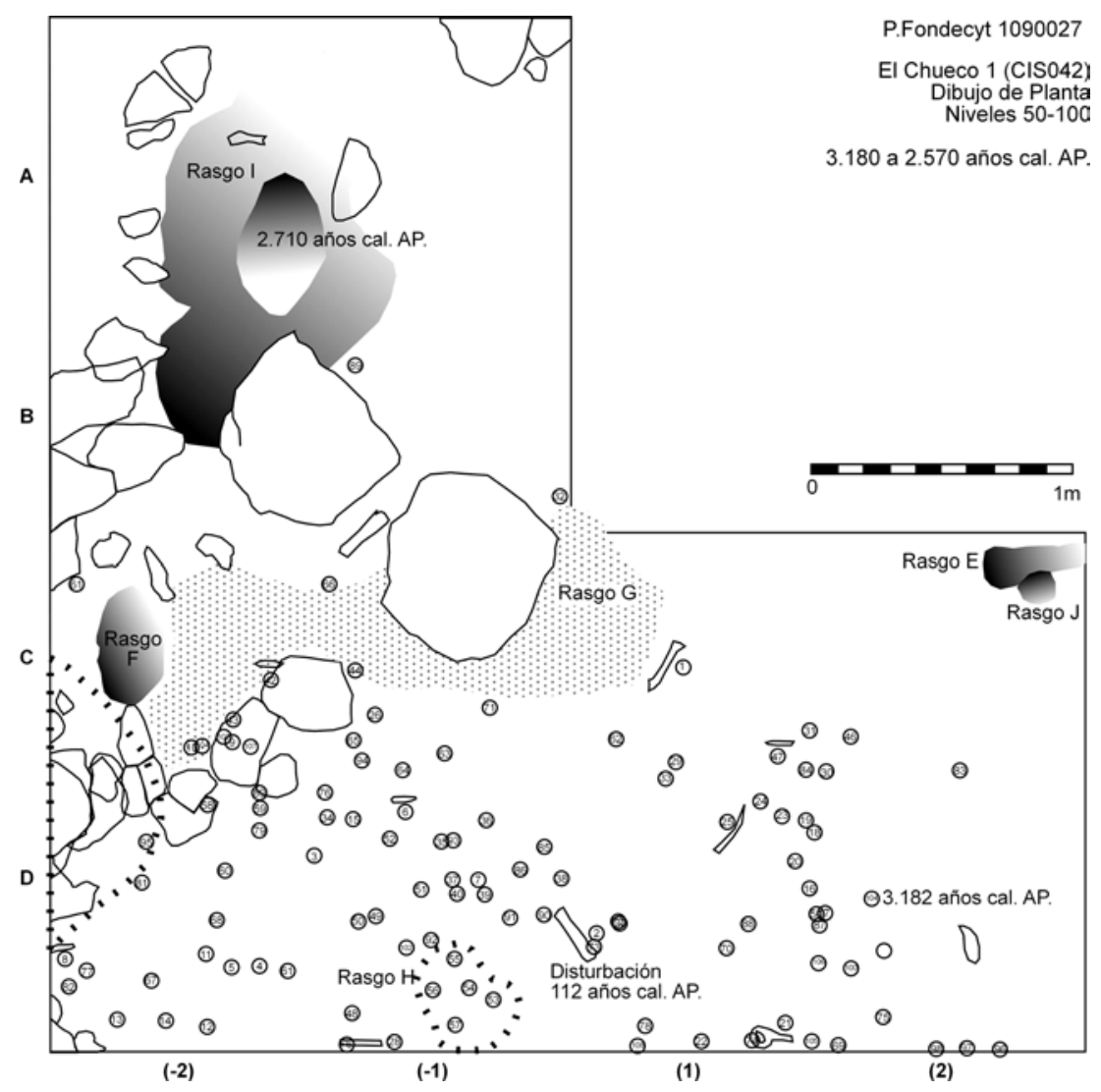

Fig. 5. Planta de la excavación de CIS 042 (año 2009) superponiendo los niveles entre 50 y $100 \mathrm{~cm}$ de profundidad, bloque Holoceno tardío. Se muestran rasgos, registros de planta y edades ${ }^{14} \mathrm{C}$ (medianas en años cal. AP). 
Tabla 5. Resultados descriptivos de los análisis de las concentraciones óseas de roedores en CIS 042.

\begin{tabular}{|c|c|c|c|c|c|c|}
\hline Rasgo & Unidad & Nivel $(\mathrm{cm})$ & Vol. flotado $\left(\mathrm{cm}^{3}\right)$ & Sedimentos & NME & NMI \\
\hline F (fogón) & $\mathrm{c}(-2)$ & $60 \mathrm{a} 70$ & 1000 & $65 \%$ & 1551 & 73 \\
\hline G (c. roedores) & $\mathrm{c}(-1)$ & $50 \mathrm{a} 60$ & 900 & $7 \%$ & 39 & 4 \\
\hline G (c. roedores) & $\mathrm{c}(-2)$ & $60 \mathrm{a} 70$ & 1350 & $56 \%$ & 14 & 4 \\
\hline C. roedores & $\mathrm{b}(-1)$ & $40 \mathrm{a} 50$ & 450 & $52 \%$ & 2197 & 113 \\
\hline C. roedores & $\mathrm{d}(-2)$ & $80 \mathrm{a} 90$ & 1450 & & 703 & 10 \\
\hline
\end{tabular}

\section{CONJUNTOS MATERIALES}

El análisis de los conjuntos materiales en un sitio como El Chueco 1 reviste una complejidad importante por cuanto resulta difícil asignar edades a niveles de excavación arbitrarios, procedimiento que fue necesario en un contexto con una masiva incorporación de clastos. Si bien este problema trató de subsanarse por medio de la realización de múltiples edades ${ }^{14} \mathrm{C}$, los límites entre bloques poseen error y no son estrictos, ya que se observó piezas que migraron, como lo atestiguan algunos restos óseos directamente fechados y algunas piezas líticas en los niveles donde no se registró otros elementos que respaldaran consistentemente la presencia humana. Aún así, integrando toda la evidencia, incluyendo rasgos, frecuencias artefactuales y restos óseos, fue posible asignar niveles a los bloques temporales a fin de discutir las tasas de depositación y los conjuntos.

Lítico

El material lítico corresponde al conjunto arqueológico más reducido en el sitio $(\mathrm{N}=88$, Tabla 6, Figura 6), previa exclusión de fragmentos dudosos de riodacita de la formación de la cueva y fragmentos y nódulos de obsidiana tipo Cisnes que se dan de forma natural en la localidad. Éste se distribuye entre los seis bloques temporales identificados. La muestra se compone en su mayoría de piezas completas y/o fragmentos proximales $(65,52 \%)$ lo que apoya un contexto con baja tasa de fragmentación. La mayor incidencia de fragmentación se observa en los derivados de talla, donde es lógico esperar una menor resistencia mecánica. Dado lo reducido de la muestra, en las observaciones a continuación no se discrimina entre piezas completas y fracturadas. En términos generales el conjunto se caracteriza por una significativa variabilidad de materias primas $(\mathrm{N}=23)$, diferentes entre cada bloque temporal, por lo que fue necesario agruparlas y discutirlas en términos de su calidad para la talla. Asimismo, si bien en el conjunto dominan los derivados de talla lítica, el alto porcentaje de instrumentos $(32,95 \%)$ y la baja cantidad de de desechos, permiten sugerir que la producción de instrumental no fue la actividad prioritaria en ninguna de las ocupaciones.

Para el bloque temporal definido entre los 3.180 y 2.570 años cal. AP $(40$ a $100 \mathrm{~cm})$ se observa un total de 1,8 piezas por $\mathrm{m}^{3}$, domina la presen-

Tabla 6. Categorías líticas representadas de acuerdo a los bloques temporales (en años cal. AP.) de CIS 042, *niveles entre bloques temporales, ** pieza con múltiples bordes retocados y usados.

\begin{tabular}{|c|c|c|c|c|c|c|c|c|}
\hline Categorías & $3.180-2.570$ & $5.520-5.400$ & $6.930-6.780$ & $*$ & $9.230 \geq 7.700$ & $10.180-9.890$ & 11.500 & Total \\
\hline Bola & 1 & - & - & - & - & - & - & 1 \\
\hline Percutor & 1 & - & - & - & - & - & - & 1 \\
\hline Cepillo & 1 & - & - & - & - & - & - & 1 \\
\hline Denticulado & - & 1 & - & 1 & - & - & - & 2 \\
\hline Bifaciales & - & 1 & - & 1 & - & - & - & 2 \\
\hline Hojas uso/retoque & - & 4 & 1 & - & - & 1 & - & 6 \\
\hline Lasca retocada & 1 & - & 1 & 2 & - & 1 & - & 5 \\
\hline Raspador & 1 & - & 2 & - & - & - & - & 3 \\
\hline Raedera** & - & - & - & - & - & - & 1 & 1 \\
\hline Nódulo astillado & 1 & 1 & - & - & - & 2 & - & 4 \\
\hline Núcleo & - & 1 & 1 & - & - & 1 & - & 3 \\
\hline Derivados de talla & 11 & 11 & 18 & 3 & 11 & 4 & $1(\dot{c} ?)$ & 59 \\
\hline Total & 17 & 19 & 23 & 7 & 11 & 9 & 2 & 88 \\
\hline
\end{tabular}



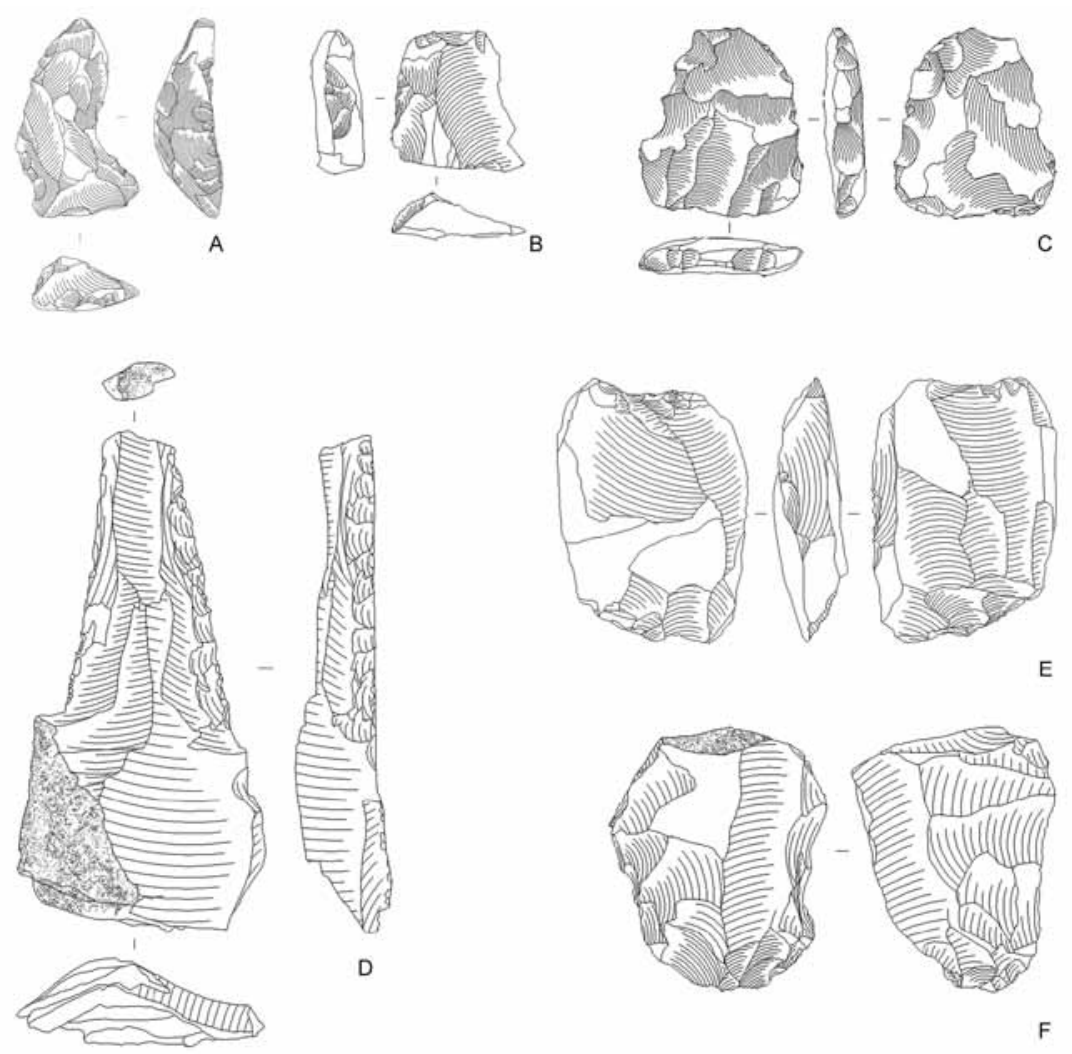

D
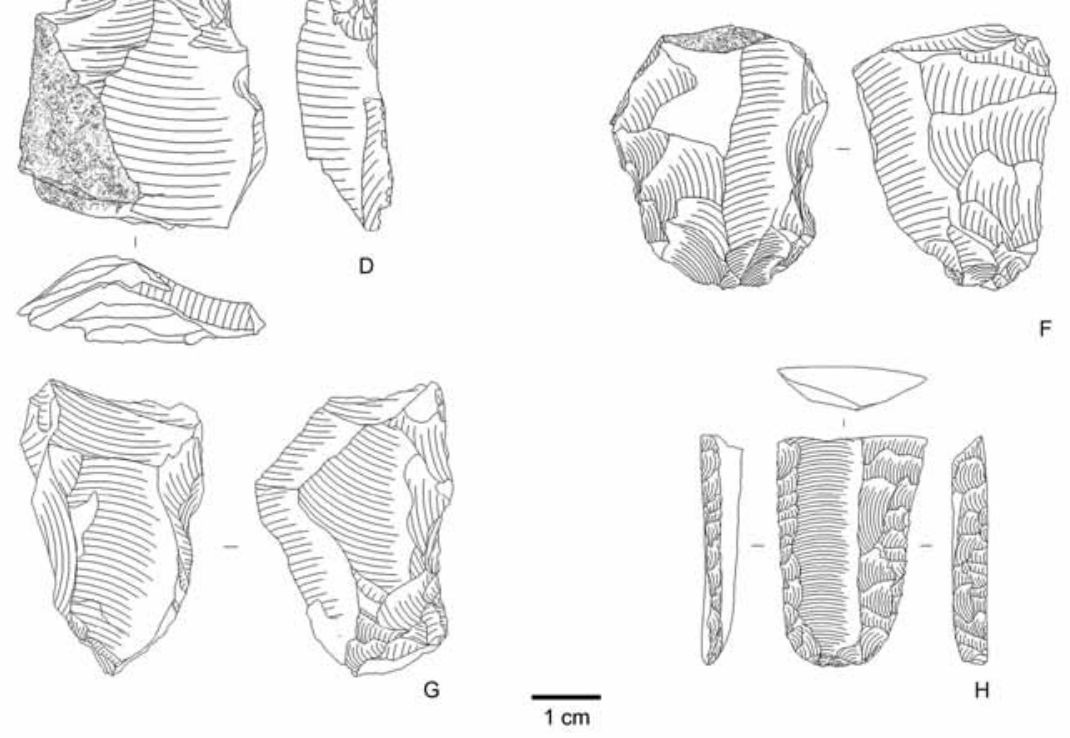

Fig. 6. Material lítico de CIS 042. A. pieza retocada (obsidiana [fuente desconocida], CIS 042 exterior); B. lasca retocada (sílice, unidad c(-1), H. tardío); C. punta de proyectil triangular retomada (obsidiana [PDA1], unidad c(-1), H. medio 2); D. hoja/lámina retocada (ślice, unidad b(-2), H. medio 2), E. núcleo bipolar (sílice, unidad c(-2), H. medio 1); F. raspador de dorso alto (ślice, unidad d(2), H. medio 1); F.; G. núcleo (sílice, unidad d(-1), H. temprano 1); H. hoja/lámina retocada (sílice, unidad d(-1), H. temprano 1).

cia de derivados de talla y se destaca una amplia variabilidad de materias primas, especialmente de calidades bajas. Clases artefactuales destacables en este bloque son un raspador frontal, una bola lítica y un cepillo sobre lasca; mientras que evidencias de tecnología bifacial, como es esperable en sitios a cielo abierto del Holoceno tardío (Méndez et al. 2007), están del todo ausentes.
El lapso entre los 5.520 y 5.400 años cal. AP (100 a $130 \mathrm{~cm}$ ) está representado por una mayor abundancia de piezas $\left(4\right.$ por $\left.\mathrm{m}^{3}\right)$. En este bloque, si bien dominan los derivados de talla, los instrumentos aparecen en un $42,11 \%$, cifra que sugiere muy baja producción y significativo uso de instrumentos y descarte. En este nivel se observó la más alta frecuencia de hojas, las que se caracterizan 
por una alta proporción de borde retocado. Entre las materias primas dominan las de alta calidad, destacando una gran variabilidad de sílices. A ello se suma una evidencia en obsidiana de la fuente de Pampa del Asador (variedad 1) (Espinosa y Goñi 1999, Stern 1999), localizada $358 \mathrm{~km}$ hacia el sur (Méndez et al. 2008/9), correspondiente a una punta de proyectil triangular retomada como raspador (Méndez et al. 2011).

Entre los 6.930 y 6.780 años cal. AP (130 a $150 \mathrm{~cm}$ ) se registra la mayor densidad de material lítico, 7,2 piezas por $\mathrm{m}^{3}$. Dominan los derivados de talla y las sílices son las materias primas más frecuentes. En este segmento, las calidades para la talla corresponden a niveles altos y medios y se destaca un desecho de talla en la obsidiana local. Si bien es cierto hay tecnología en hojas y desechos de adelgazamiento bifacial, estas evidencias son minoritarias. Entre las clases artefactuales destaca un núcleo bipolar agotado y un raspador de dorso alto. En el espacio entre el fin de este bloque temporal y el inicio del siguiente, se detectó la presencia de algunas evidencias líticas, no obstante, en estos niveles no ha sido posible identificar rasgos de ocupación humana u otros materiales asociados. No se descarta, entonces, que los líticos puedan haber migrado verticalmente al ser partículas menores.

Para el bloque entre los 9.230 y antes de los 7.700 años cal. AP (170 a $190 \mathrm{~cm}$ ) los artefactos aparecen en una frecuencia de 3,4 por $\mathrm{m}^{3}$, siendo el único segmento sin instrumentos. Adicionalmente, la variabilidad de materias primas decrece y este nivel se caracteriza por calidades medias a bajas.

En el segmento estratigráfico entre los 10.180 y 9.890 años cal. AP (190 a $210 \mathrm{~cm}$ ) el panorama cambia nuevamente $\mathrm{y}$, si bien se observa también una baja frecuencia de material (2,8 piezas por $\left.\mathrm{m}^{3}\right)$, destaca la presencia de obsidiana de Pampa del Asador (variedad PDA1) y una muestra con elementos traza muy similares a las de Sierra Negra (T/SC?, Méndez et al. 2011) de la Meseta de Somuncurá (Stern et al. 2000, Gómez Otero y Stern 2005), localizada a $460 \mathrm{~km}$ hacia el noreste (Méndez et al. 2008/9). Ambas piezas se recuperaron en el mismo nivel en unidades de excavación contiguas. Las calidades de las rocas son variadas y no se observan tendencias específicas a favor de alguna. En la muestra dominan los instrumentos con un $55,56 \%$. En este bloque fue posible recuperar una hoja retocada en sílice de alta calidad, un núcleo multidireccional reutilizado como muesca y una lasca retocada. El material cultural asociado a la fecha de 11.500 años cal. AP (fondo cueva, extremo NE excavación, 200 a $210 \mathrm{~cm}$ ) corresponde sólo a un instrumento multifuncional en microgranodiorita con varios bordes activos, cuya función principal fue aparentemente el raído. La pieza y la edad asociada sobre espícula de carbón fueron registradas en las excavaciones iniciales del sitio (unidad a(2); Reyes et al. 2007), y no han podido ser replicadas en la ampliación. Sólo una lasca de sílice fue recuperada en relativa proximidad al hallazgo anterior [unidad b(-1)] y podría eventualmente relacionarse.

A manera de síntesis, es posible señalar que si bien la muestra es pequeña y en gran medida no pueden derivarse tendencias (p.e. no resiste análisis distribucionales), ésta destaca por estar constituida por una gran cantidad de instrumentos; cuestión que apoya contextos de uso y descarte, por sobre actividades de producción lítica. A ello se asocia una gran diversidad de clases artefactuales, donde destaca la alta formalidad de los diseños y el importante reactivado de sus filos, lo que hace suponer estrategias de prolongación de la vida útil y alto transporte. Ello se ha visto ratificado en el caso de algunas materias primas como la obsidiana de fuentes distantes. A su vez, destaca la gran variabilidad selectiva en las rocas y dominan las calidades excelentes a muy buenas. Ningún conjunto por bloque temporal resulta consistente como para discutir actividades comunes o contextos funcionalmente integrados, lo que sugiere que la muestra se compone de la pérdida/descarte incidental del equipo personal de transporte de los ocupantes del sitio, en una lógica de eventos discretos bajo el reparo.

\section{Arqueofauna}

Los restos óseos más comunes en el sitio corresponden a microfauna. Para su estudio se llevó a cabo un muestreo sistemático con una intención cuantitativa de los rasgos donde se observaron acumulaciones (Tabla 5). Éstos se distinguen en la Unidad Estratigráfica 4 en la forma de dos rasgos denominados CR1 y CR2 (Figura 3) y en planta entre los 50 y $70 \mathrm{~cm}$ como Rasgo G (Figura 5). La microfauna recuperada está constituida por grupos de vertebrados menores (reptiles, anfibios, 
aves y roedores) que por su condición de baja masa corporal, hábitos preferentemente nocturnos, baja predictibilidad y/o presencia en rasgos de acumulación, sugieren un origen no-antrópico (Jackson 2010). Un segundo aspecto que se puede inferir es que los roedores (principal grupo representado) no han sido agentes perturbadores del contexto arqueológico, su depositación fue pasiva y aunque se encontraron restos de Ctenomys magellanicus, que es una especie fosorial, su hábitat no son los reparos rocosos sino espacios abiertos. Se puede concluir que el origen de los microvertebrados recuperado en el sitio es natural, y que el depósito de acumulación se formó a través de regurgitados (egagrópilas) de aves rapaces (Strigiformes).

Respecto a la fauna mayor, existen varios taxa representados en el depósito con un dominio continuo del L. guanicoe a lo largo de toda la secuencia (Tabla 7; Trejo y Velásquez 2011). Excepcionalmente, se registró un dominio de 0 . aries en los $40 \mathrm{~cm}$ superiores del depósito, bloque correspondiente a tiempos subactuales/históricos, en donde los restos óseos sugieren procesos de incorporación principalmente naturales. En términos generales, una evaluación de la frecuencia de partes esqueletarias de L. guanicoe y sus valores de densidad mineral ósea, sugieren que la segunda habría tenido una relativa baja incidencia en la conformación del conjunto en su totalidad (test
Rho de Spearman; bloque 3.180 y 2.570 años cal. AP, $r_{s}$ : -0,00751, p.: 0,7298; bloque 5.520 y 5.400 años cal. AP, $r_{s}: 0,1434$, p.: 0,569; bloque 6.930 y 6.780 años cal. AP, $r_{s}: 0,354$, p.: 0,283). Asimismo, el conjunto muestra una baja tasa de meteorización y una minoritaria frecuencia de huellas de roedores y carnívoros, siendo el pisoteo el mayor agente de daño sobre los huesos.

Para los restos registrados en los niveles correspondientes al Holoceno tardío (40 a $100 \mathrm{~cm}$ ), la variedad y riqueza de taxones es relativamente alta, y los restos de L. guanicoe son los más abundantes, aun cuando su densidad es más bien baja (20 especímenes por $\mathrm{m}^{3}$ ). Los perfiles esqueletarios sugieren que las presas ingresaron completas al sitio. El MNI y las edades inferidas indican que habrían ingresado un individuo adulto y tres subadultos, lo que apoya la idea de ocupaciones estivales (Raedeke 1978). La evidencia de huellas de corte y sus ubicaciones indican que se llevaron a cabo actividades de desmembramiento, fileteo y desarticulación. Por otra parte, fracturas asociadas a marcas de percusión y un espécimen con corte perimetral sugieren consumo de médula y/o manufactura de instrumentos.

Para el bloque temporal entre (100 a $130 \mathrm{~cm})$, observamos que la riqueza taxonómica disminuye, al igual que el número de restos asignados a $L$. guanicoe, los que ocurren con una frecuencia de 13

Tabla 7. Conjuntos óseos de fauna mayor de acuerdo a los bloques temporales (en años cal. AP.) de CIS 042, entre paréntesis: porcentaje del NISP por bloque temporal.

\begin{tabular}{|c|c|c|c|c|c|c|c|c|}
\hline \multirow{2}{*}{ Taxa } & \multicolumn{2}{|c|}{ Histórico/subactual } & \multicolumn{2}{|l|}{$3.180-2.570$} & \multicolumn{2}{|c|}{$5.520-5.400$} & \multicolumn{2}{|c|}{$6.930-6.780$} \\
\hline & NISP & MNI & NISP & MNI & NISP & MNI & NISP & MNI \\
\hline Artiodactyla & $1(1,8)$ & - & $8(3,0)$ & - & $3(3,8)$ & - & - & - \\
\hline Lama guanicoe & $3(5,5)$ & 1 & $160(59,9)$ & 4 & $63(78,8)$ & 3 & $22(88)$ & 2 \\
\hline Ovis sp. & $24(43,6)$ & 2 & $60(22,5)$ & 3 & - & - & - & - \\
\hline Carnivora & - & - & $5(1,9)$ & - & - & - & - & - \\
\hline Felidae & $1(1,8)$ & 1 & - & - & - & - & - & - \\
\hline Puma concolor & - & - & $1(0,4)$ & 1 & $2(2,5)$ & 1 & - & - \\
\hline Canidae & $3(5,5)$ & 1 & $26(9,7)$ & 3 & $7(8,8)$ & 1 & $2(8)$ & 1 \\
\hline Lycalopex griseus (?) & - & - & $2(0,7)$ & 2 & - & - & - & - \\
\hline Dusicyon avus & - & - & - & - & - & - & $1(4)$ & 1 \\
\hline Mustelidae & $2(3,6)$ & 1 & - & - & - & - & - & - \\
\hline Euphractus (Zaedyus) pichiy & $20(36,4)$ & 1 & $2(0,7)$ & 1 & - & - & - & - \\
\hline Mamífero pequeño & - & - & - & - & $1(1,3)$ & - & - & - \\
\hline Passeriformes & - & - & $1(0,4)$ & - & $3(3,8)$ & - & - & - \\
\hline Aves medianas & $1(1,8)$ & - & $2(0,7)$ & - & $1(1,3)$ & - & - & - \\
\hline Total & $55(100)$ & 7 & $267(100)$ & 14 & $80(100)$ & 5 & $23(100)$ & 4 \\
\hline
\end{tabular}


especímenes por $\mathrm{m}^{3}$. De acuerdo a las frecuencias observadas, las presas ingresaron completas al sitio y de acuerdo a las escasas huellas de corte registradas, se pueden señalar tentativamente actividades de cuereo y fileteo. Las marcas de percusión asociadas a fracturas también sugieren consumo de médula. Las edades representadas indican el ingreso de dos adultos y un subadulto en el sitio, nuevamente indicando ocupación estival.

Entre los 6.930 y 6.780 años cal. AP (130 a $150 \mathrm{~cm}$ ) los restos óseos son sumamente discretos y escasamente variados. L. guanicoe está representada por 4,5 especímenes por $\mathrm{m}^{3}$. Las marcas humanas registradas son escasas, y sólo una sugiere desarticulación. Los perfiles etarios y MNI no apoyan una presencia clara de subadultos en este conjunto. Adicionalmente, resulta significativo que en este bloque se registró un espécimen de Ducisyon avus, taxa que se sabe estuvo disponible en la región en fechas del orden de 7.860 años cal. AP (Velásquez y Mena 2006).

En definitiva, podemos concluir que L. guanicoe es el taxa mayormente representado a través de toda la secuencia. El registro de otros animales es mucho menor y su consumo es discutible. Se puede señalar que las carcasas -especialmente en los componentes post 5.520 años cal. AP-ingresaron completas al sitio. La variabilidad de huellas de corte, por su parte, indica que se realizaron todas las actividades de la cadena productiva, desde el trozado primario en adelante. La muestra arqueofaunística disminuyó progresivamente durante la excavación, y desapareció por completo bajo los $150 \mathrm{~cm}$ de profundidad (unidad estratigráfica 5), por lo que no hay restos de fauna asociados a los niveles tempranos del sitio. Si bien los análisis de $\mathrm{PH}$ muestran valores ácidos (Tabla 2), las diferencias no son suficientemente significativas como para explicar la buena conservación del material óseo en la unidad estratigráfica 4 y la ausencia total de restos en la unidad estratigráfica 5 . Por su parte, los valores más bajos de fósforo se registraron precisamente en esta última, lo que sugiere que no hubo degradación de restos óseos.

\section{Carporrestos}

Si bien se recuperó un conjunto importante de restos carpológicos $(n=913)$ en los muestreos, se debe señalar que la mayor parte corresponde a restos no carbonizados (59,47\%), los que tienen alta probabilidad de haber ingresado al sitio por agentes post-depositacionales (Belmar 2010). Considerando los volúmenes procesados, la densidad calculada (27,87 carporrestos/l) es baja, especialmente al considerar los restos quemados (11,25 carporrestos/l). Consecuentemente, la información más rica proviene de las muestras obtenidas en rasgos de combustión. El conjunto analizado posee baja variabilidad, y se compone de los siguientes taxa: Berberis sp. (0,5\%), Brassicaceae (34,4\%), Chenopodiaceae (17,3\%), Galium sp. (4\%), Lamiaceae (6,2\%), cf. Phacelia sp. (0,2\%), Poaceae (1,1\%), Polygonaceae $(2,8 \%)$ y Scirpus sp. (1\%). Se observa mayor variabilidad y frecuencia de restos en los rasgos del bloque entre 3.180 y 2.570 años cal. AP, que en los niveles más profundos, donde la diversidad y cantidad decrecen progresivamente. La alta frecuencia de herbáceas como Chenopodiaceae y Brassicaceae (entre otras) y su hallazgo en las estructuras de combustión sugieren que en su mayoría estuvieron orientadas a la quema, especialmente en ausencia de indicadores de plantas leñosas. Si bien Chenopodiaceae y Scirpus sp. son consumibles como alimento, no existen consistentes indicadores para ello. Finalmente, destaca que en los rasgos I (2.710 años cal. AP) y N (6.928 años cal. $\mathrm{AP})$ se haya recuperado carporrestos de Berberis sp., que si bien es probable también haya operado como combustible, la presencia de frutos y semillas indicaría estacionalidad estival.

\section{DISCUSIÓN: OCUPACIONES HUMANAS EN EL CHUECO 1 Y CORRELACIÓN REGIONAL}

Los bloques temporales ocupados para la interpretación de los patrones materiales en el sitio no corresponden a ocupaciones propiamente, sino los usamos como rangos cronológicos que enmarcan la evidencia. La observación de la disposición de los rasgos en la excavación y la escasez de material cultural registrado permiten sugerir que el depósito del sitio El Chueco 1 se formó a partir de una serie de eventos puntuales de muy baja intensidad, aunque reiterados sobre un mismo espacio. Nos parece que la mejor forma de considerar estos eventos es a partir de la cuantificación de los rasgos discretos de acción humana más frecuentes, en este caso, las estructuras de combustión. Esta unidad de análisis 
es la más apropiada para ponderar la ocupación de un espacio discreto, que ofreció limitadas oportunidades de reparo, pero se constituyó como un punto reconocido, al cual acudir por breves a muy breves estadías. Utilizamos la noción de "evento" para caracterizar la ocurrencia de estas estadías registradas arqueológicamente. Finalmente, por su condición de aislamiento y unicidad, los eventos identificados en El Chueco 1, además pueden ser considerados como medidores de pulsos de presencia humana en la región inmediata al Alto Cisnes.

Una síntesis cronológica de las evidencias establece un inicio de la ocupación del sitio y de la región hacia los 11.500 años cal. AP (Méndez et al. 2009). La débil señal arqueológica al interior de la cueva sólo está caracterizada por una edad ${ }^{14} \mathrm{C}$ asociada a un instrumento lítico al NE de la excavación. No se ha podido detectar dicha ocupación en las excavaciones ampliadas del sitio y es necesario ser cautelosos. Sin embargo, en la misma fecha en la columna de sedimentos de Lago El Shaman (a 6 $\mathrm{km}$ ) se marca el inicio de la depositación de partículas de carbón indicadoras de fuegos locales, lo que ha sido discutido previamente como una señal humana a nivel del área (Méndez et al. 2010a).

Grupos humanos posteriores hacen uso de la localidad también de forma muy discreta, aunque con una mayor tasa de descarte de artefactos líticos en dos bloques, primero entre los 10.180 y 9.890 años cal. AP y luego alrededor de los 9.230 años cal. AP, con una edad mínima 7.700 años cal. AP. $\mathrm{Al}$ igual que en el caso anterior, en estos niveles no se han detectado restos óseos, lo que se interpreta como una decisión cultural en atención a los análisis químicos realizados. Probablemente, los eventos ocupacionales no incluyeron el transporte de carcasas o segmentos de ellas a un sitio que fue visitado con una intensidad mínima. Si bien los conjuntos artefactuales son muy limitados, la excepcional presencia de dos desechos de talla de obsidiana en el bloque entre 10.180 y 9.890 años cal. AP procedentes de dos fuentes muy distantes entre sí implicaría rangos de movilidad muy amplios, superposición de rangos de acción de distintos grupos en el sitio, o eventualmente interacciones que pudieron suceder a escala espacial amplia (Figura 1). Esto viene a corroborar resultados antes logrados con muestras superficiales que sugerían la confluencia de estos amplios rangos de transporte de materias primas en el curso alto del río Cisnes (Méndez et al. 2008/9), aunque ahora con edades ${ }^{14} \mathrm{C}$ asociadas.

Entre los 7.700 y 6.930 años cal. AP se observan niveles donde no se registraron estructuras de combustión, los artefactos decrecen y tampoco hay presencia de restos óseos. La fecha inicial proviene de un rasgo de Festuca preservado entre rocas que lo comprimieron. Esta evidencia, junto a los elementos anteriores, podría estar sugiriendo una colonización vegetal del interior del reparo en un período de desocupación del sitio.

Hacia los 6.930 años cal. AP se inician ocupaciones breves, aunque un poco más intensas. El material lítico aumenta, al igual que la frecuencia y tamaño de los rasgos de actividad de combustión y se suman los restos de fauna. Se han podido detectar dos bloques temporales diferenciados verticalmente y cada uno con dos edades ${ }^{14} \mathrm{C}$ muy similares entre sí. El primer bloque se extiende entre los 6.930 y 6.780 años cal. AP y el segundo, entre los 5.520 y 5.400 años cal. AP Ambos presentan evidencias de tecnología bifacial y de hojas en distinta frecuencia; además de selectividad de recursos líticos de alta calidad. Entre los últimos se destaca también obsidiana de Pampa del Asador. La formalidad de los diseños instrumentales y su alto reciclado se suman a lo anterior para apoyar la idea que estos grupos desarrollaron amplios rangos de movilidad. Si bien es cierto los restos de fauna son escasos, hay evidencias de procesamiento de L. guanicoe, con un ingreso de carcasas completas y perfiles etarios que apoyan estacionalidad estival. Esto se corrobora con la presencia de frutos y semillas de Berberis sp. en una de las estructuras de combustión. La ocupación estival de los sitios del Alto Cisnes había sido previamente propuesta sobre la base de la cubierta de nieve característica del invierno a esta altitud (900 msnm, Reyes et al. 2006).

Por su parte, las ocupaciones del Holoceno tardío se extienden en un rango más extenso entre los 3.180 y 2.570 años cal. AP lo que nos permite suponer que corresponden a eventos superpuestos indiferenciados. Las edades ${ }^{14} \mathrm{C}$ para este paquete temporal incluyen una muestra intrusiva (muy desviada) que, junto a evidencias de restos de Ovis aries, acusan disrupción estratigráfica, especialmente manifiesta en la unidad estratigráfica 3. En los perfiles del área de alta energía se observaron flujos de clastos en este segmento estratigráfico, indicando 
procesos más violentos de incorporación de partículas mayores. Si bien la frecuencia de material lítico es similar y los restos de fauna aumentan con respecto a los eventos descritos anteriormente, un análisis de las tasas de depositación por intervalos de tiempo estandarizados (restos $/ 100$ años $/ \mathrm{m}^{2}$ ) permite sugerir que los testigos de actividad humana son aún más efímeros (Figura 7). El material lítico exhibe un uso de materias primas de calidades más bajas y sujetas a menor transporte, lo que es consistente con una ocupación más extendida del área local, como lo atestigua la mayor presencia de sitios contemporáneos en las proximidades (Méndez y Reyes 2008). Los restos de L. guanicoe muestran un ingreso completo de las presas, evidencias de toda la cadena operativa de procesamiento de las carcasas y restos de individuos preferentemente subadultos que apoyan eventos durante la temporada estival. Lo anterior se ve ratificado con las evidencias carpológicas.

Si bien es cierto no han sido registrados eventos ocupacionales en El Chueco 1 posteriores a los 2.570 años cal. AP, sí se han documentado diversas ocupaciones cercanas al sitio entre esta fecha y hasta los 650 años cal. AP (Reyes et al. 2009; Reyes y Méndez 2010). Ello implica que el reparo dejó de ser usado en función de otras alternativas a cielo abierto que han sido sistemáticamente registradas en el curso alto del río Cisnes (Reyes et al. 2006).

A escala regional, el sitio con mayores atributos comparables a lo descrito es Baño Nuevo 1, localizado $120 \mathrm{~km}$ al Sur de El Chueco 1. Ambos se emplazan sobre el área de Relieves Planiformes Orientales, en altitudes sobre 750 msnm y se encuentran rodeados de vegetación de estepa. Ambas cuevas son únicas en el entorno circundante, aunque sólo El Chueco podría considerarse como un punto destacado de alta visibilidad a nivel local. Los rangos temporales de ocupación son similares, aunque en el caso de Baño Nuevo 1 se han propuesto bloques temporales más extensos: Componente temprano de $10.750 \mathrm{a}$ 8.800 años cal. AP, Componente medio de 8.800 a 5.660 años cal. AP y Componente tardío de 5.660 a 3.100 años cal. AP (Velásquez y Mena 2006). En el Componente temprano de Baño Nuevo 1 se registraron un total de 10 entierros humanos en el rango entre 10.150 a 9.820 años cal. AP sobre la base de edades ${ }^{14} \mathrm{C}$ directas (Mena y Stafford 2006, Mena et al. 2010), lo que apoya una excepcional

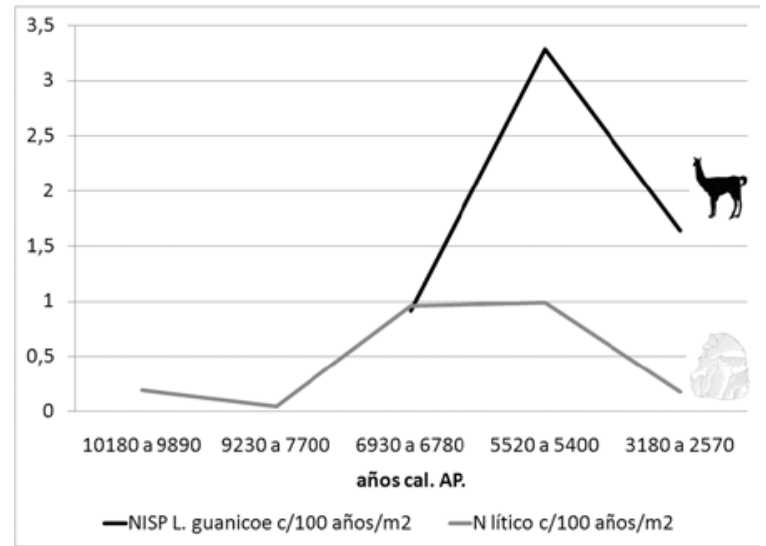

Fig. 7. Tasa de depositación de material óseo (NISP de L. guanicoe) y lítico por bloques temporales en CIS 042.

señal humana para este momento en Patagonia. En relación al registro faunístico, mientras que $\mathrm{El}$ Chueco 1 muestra una discreta proporción de restos óseos sólo vinculados al consumo de L. guanicoe, Baño Nuevo 1 presenta una mayor diversidad selectiva y cantidad de evidencias (Trejo y Jackson 1998, Mena et al. 2000, Velásquez y Mena 2006, Mena 2009). En términos tecnológicos, si bien los conjuntos poseen diferencias (García 2007), ambas cuevas comparten la presencia de obsidiana de Pampa del Asador (Espinos y Goñi 1999, Stern 1999), aunque sólo El Chueco muestra conexiones eventuales con la meseta de Somuncura (Méndez et al. 2011). El hecho que El Chueco esté contextualizado en su área circundante (Reyes et al. 2006) y que Baño Nuevo 1 no, establece la prioridad de llevar a cabo trabajos de prospección en el valle de Nirehuao a fin de comprender localmente tan significativos hallazgos.

\section{CONCLUSIONES}

El sitio El Chueco 1 corresponde a una localidad arqueológica con múltiples eventos de ocupación humana con una resolución contextual muy baja. No obstante, se ha podido precisar la extensión temporal de algunos de los eventos y ponderar los datos recabados por los análisis de los conjuntos arqueológicos. La reiteración del uso del espacio al interior del reparo es, sin dudas, una de las características más singulares del sitio. Esta reiteración se manifiesta en similares patrones de ocupación del espacio interno a lo largo de una 
secuencia de eventos muy discretos. El incremento sostenido en la intensidad de su uso es sólo defendible hasta el Holoceno medio, a partir de donde disminuye el registro arqueológico de acuerdo a las tasas de depositación. La mayor cantidad de sitios con firma tardía en el resto del valle (Méndez et al. 2007, Reyes et al. 2009) muestra que hubo mayor variabilidad en los tipos de asentamientos.

Las evidencias de obsidiana en el sitio apoyan extensos rangos de movilidad que lo vinculan a las estepas de Patagonia Centro-Sur. A pesar de lo exiguo del registro, el análisis de procedencia de obsidianas reveló una variedad de Pampa del Asador durante la primera ocupación del Holoceno temprano, lo que es consistente con la evidencia de Baño Nuevo 1 (Stern 1999) y otros sitios contemporáneos (Borrero y Franco 1997, Civalero y Franco 2003). La inesperada presencia de una variedad de obsidiana muy similar a las de Telsen/Sierra Negra -a 460 km de distancia- dentro del mismo rango cronológico, amplía las posibilidades de flujos materiales en escalas amplias (Méndez et al. 2011). La presencia de materias primas líticas de fuentes lejanas en baja frecuencia y bajo la forma de artefactos formales o desechos de talla en etapas finales de reducción son esperables para la ocupación de un área marginal. Además de lo reducido de la evidencia, distintos análisis apoyan presencia humana en la estación estival, al menos para el Holoceno medio y tardío. No hay razones para suponer que ello fuera diferente durante la transición Pleistoceno Holoceno, ya que en fechas anteriores a los 8.000 años cal. AP la información de la columna de lago El Shaman muestra condiciones de menor humedad efectiva y posiblemente más frías (Reyes et al. 2009). La altitud y ubicación en las estribaciones cordilleranas del área del Alto Cisnes probablemente redundaron en restricciones estacionales para su ocupación. En dicho sentido, la lógica de eventos breves a muy breves que detectamos en el sitio, no son sino un reflejo de lo que esperamos para el uso de zonas periféricas ocupadas desde las estepas orientales (Borrero 2004).

El Chueco 1 muestra presencia humana en un área marginal desde 11.500 años atrás. La señal arqueológica en el sitio y la región fue siempre débil a lo largo de su ocupación, no obstante quedó preservada a través de evidencias materiales al interior de la cueva. A pesar de haber buscado otros sitios de edad contemporánea que teóricamente debieran existir en la región inmediata, su identificación no ha tenido resultados positivos (Méndez et al. 2010b). En dicho sentido El Chueco 1 se mantiene como una buena alternativa que, aunque con limitantes, puede utilizarse para entender las ocupaciones humanas en la margen occidental de la estepa de Patagonia Central.

\section{AGRADECIMIENTOS}

Financiado por FONDECYT 1090027. Agradecemos a Estancia Río Cisnes, especialmente a Stephanie Buckaert y Eduardo Batarce. Agradecemos a Charles Stern (University of Colorado) por los análisis ICP-MS en muestras de obsidiana. Las siguientes personas apoyaron en algunos de los análisis conducidos: Carolina Belmar, Antonio Maldonado, Douglas Jackson, Donald Jackson, Cristina Ortega, Gregorio Calvo, Catalina Contreras y Gisella Morety; y las siguientes personas apoyaron en actividades de terreno: Francisco Mena, Pablo González, Pablo Larach, Carlos Uribe y Leonardo Zúñiga. Agradecemos especialmente a Juan Bautista Belardi por sus valiosos comentarios al manuscrito.

\section{BIBLIOGRAFÍA}

ARAGÓN, E. y N. FRANCO 1997. Características de rocas para la talla por percusión y propiedades petrográficas. Anales del Instituto de la Patagonia, Serie Cs. Humanas, 25:187-199.

BELMAR, C. 2010. Informe de carporrestos, sitio alero El Chueco 1 (CIS 042), curso superior valle del río Cisnes, XI Región de Aisén. En: Informe proyecto FONDECYT 1090027, año 1, compilado por C. Méndez y O. Reyes. Santiago, MS.

BEHRENSMEYER, A.K. 1978. Taphonomic and ecologic information from bone weathering Paleobiology, 4(2):150-62.

BINFORD, L. 1981. Bones: Ancient Men and Modern Myths. Academic Press, New York.

BINFORD, L. 1984. Faunal Remains from Klasies River Mouth. Academic Press, Orlando.

BORRERO, L.A. 2004. The Archaeozoology of Andean 'Dead Ends' in Patagonia: Living near the Continental Ice Cap. En: Colonisation, Migration and Marginal Areas. A Zooarchaeological approach, editado por M. Mondini, A. S. Muñoz y S. Wickler. pp 55-61. Oxbow Books, Oakville. 
BORRERO, L. y N. FRANCO 1997. Early Patagonian huntergatherers: subsistence and technology. Journal of Anthropological Research, 53:219-239.

BRONK RAMSEY, C. 2009. Bayesian analysis of radiocarbon dates. Radiocarbon, 51(1): 337-360.

CIVALERO, M. y N. FRANCO 2003. Early human occupations in western Santa Cruz Province. Southernmost South America. Quaternary International, 109-110:77-86.

ESPINOSA, S. y R. GOÑI 1999. Viven!! Una fuente de obsidiana en la provincia de Santa Cruz. En: Soplando en el viento. Actas de las III Jornadas de Arqueología de la Patagonia, pp. 177-188. Universidad Nacional del Comahue e Instituto Nacional de Antropología y Pensamiento Latinoamericano, San Carlos de Bariloche y Buenos Aires.

FIGUERERO, M. 2000. Estructuración del espacio en Cerro de los Indios 1 (Lago Posadas, Santa Cruz). En: Desde el país de los gigantes, editado por J. Belardi, F. Carballo y S. Espinosa, Tomo 2:385-400. UNPA, Río Gallegos.

GALANIDOU, N. 2000. Patterns in caves: foragers, horticulturists, and the use of space. Journal of Anthropological Archaeology, 19:243-275.

GARCÍA, C. 2007. Conjuntos líticos y estrategias tecnológicas de las ocupaciones humanas de la cuenca de Baño Nuevo-1 (XI Región de Aisén, Chile). En: Arqueología de Fuego-Patagonia. Levantando piedras, desenterrando huesos... develando arcanos, editado por F. Morello, M. Martinic, A. Prieto y G. Bahamonde, pp. 493-502. Ediciones CEQUA, Punta Arenas.

GÓMEZ OTERO, J. y C. STERN 2005. Circulación, intercambio y uso de obsidianas en la costa de la provincia del Chubut (Patagonia Argentina), durante el Holoceno tardío. Intersecciones en Antropología, 6:93-108.

GRAYSON, D. 1984. Quantitative Zooarchaelogy. Academic Press, New York.

GREIG, J. 1989. Archaeobotany. Handbooks for Archaeologist 4. European Science Foundation, Strasbourg.

INIZAN, M., M. REDURON, H. ROCHE y J. TIXIER 1995. Technologie de la pierre taillée. CREP, Meudon.

JACKSON, D. 2002. Los instrumentos líticos de los primeros cazadores de Tierra del Fuego. Ensayos y Estudios. DIBAM, Santiago.

JACKSON, D. 2007. Estructura, intensidad y reiteración en las ocupaciones Paleoindias en cuevas y aleros de Patagonia meridional (Chile). Cazadores-recolectores del Cono Sur, 2:67-87.

JACKSON, D. 2010. Análisis de micro vertebrados del sitio El Chueco 1 (CIS 042) del Valle del Rio Cisnes (Región de Aisén). En: Informe proyecto FONDECYT 1090027 año 1, compilado por C. Méndez y O. Reyes. Santiago, MS.
KLEIN, R.G. y K. CRUZ-URIBE 1984. The Analysis of Animal Bones fron Archaeological Sites. The University of Chicago Press, Chicago.

LUEBERT, F. y P. PLISCOFF 2006. Sinopsis bioclimática y vegetacional de Chile. Editorial Universitaria, Santiago.

LYMAN, R.L. 1994. Vertebrate Taphonomy. Cambridges Manuals in Archaeology. Cambridge University Press, Cambridge.

MENA, F. 2009. Aves en cueva Baño Nuevo. Zooarqueología y tafonomía en el confín del mundo, editado por: P. López, I. Cartajena, C. García y F. Mena, pp. 59-71. Universidad Internacional SEK, Santiago.

MENA, F. y T. STAFFORD 2006. Contexto estratigráfico y fechación directa de esqueletos humanos del Holoceno Temprano en Cueva Baño Nuevo 1 (Patagonia Central, Chile). En: Segundo Simposio Internacional del Hombre Temprano en América, editado por J. Jiménez, S. González, J. Pompa y F. Ortíz, pp: 139-54. INAH, Ciudad de México.

MENA, F., O. REYES y M. MORAGA 2010. Lo nuevo de Baño Nuevo. Presentado al V Simposio Internacional. El Poblamiento Temprano de América: a un siglo del debate Ameghino-Hrdlicka. La Plata.

MÉNDEZ, C., O. REYES y H. VELÁSQUEZ 2007. Tecnología lítica en el alto río Cisnes (estepa extra andina de la XI Región de Aisén): primeros resultados. Boletín de la Sociedad Chilena de Arqueología, 39:87-101.

MÉNDEZ, C. y O. REYES 2008. Late Holocene human occupation of Patagonian forests: a case study at Cisnes river basin (44 S, Chile). Antiquity, 82:560-570.

MÉNDEZ, C., C. STERN y O. REYES 2008/9. Transporte de obsidianas a lo largo de los Andes de Patagonia Central (Aisén, Chile). Cazadores-recolectores del Cono Sur, 3: 51-68.

MÉNDEZ, C., C. STERN, O. REYES y F. MENA 2011. Early Holocene long-distance obsidian transport in CentralSouth Patagonia. Chungara Revista de Antropología Chilena, en evaluación.

MÉNDEZ, C., O. REYES, A. MALDONADO y J.P. FRANÇOIS 2009. Ser humano y medio ambiente durante la transición Pleistoceno Holoceno en las cabeceras del río Cisnes ( $44^{\circ}$ s, Aisén Norte). En: Arqueología de Patagonia: una mirada desde el último confín, editado por $\mathrm{M}$. Salemme, F. Santiago, M. Álvarez, E. Piana, M. Vázquez y E. Mansur, pp. 75-83. Editorial Utopías, Ushuaia.

MÉNDEZ, C., O. REYES, A. MALDONADO y A. MARTEL 2010a. Señales humanas para entender el poblamiento de los márgenes de la estepa de Patagonia Central. Presentado al V Simposio Internacional. El Pobla- 
miento Temprano de América: a un siglo del debate Ameghino-Hrdlicka. La Plata.

MÉNDEZ, C., O. REYES, A. NUEVO DELAUNAY y C. CONTRERAS 2010b. Criterios para evaluar ocupaciones tempranas en sitios arqueológicos superficiales, Aisén norte, Chile. En: Arqueología argentina en el Bicentenario de la Revolución de Mayo, Tomo I, pp. 85-90, Mendoza.

MENGONI, G. 1999. Cazadores de guanacos de la estepa patagónica. Colección Tesis Doctorales. Sociedad Argentina de Antropología, Buenos Aires.

ORTEGA, C. 2010. Geología y geomorfología del valle de la cabecera del Río Cisnes (Estancia Río Cisnes) durante el Cuaternario. En: Informe proyecto FONDECYT 1090027 año 1, compilado por C. Méndez y O. Reyes. Santiago, MS.

PRIETO, X., J. CORTES y M. SUAREZ 1994 Mapa Geológico del área oriental de la Hoja Puerto Cisnes. Región Aisén del General Carlos Ibáñez del Campo. (Versión preliminar) SERNAGEOMIN, Santiago.

RAEDEKE, K. 1978. El guanaco de Magallanes, Chile: distribución y biología. CONAF, Santiago.

REITZ, E. y E. WING 2000. Zooarqueology. Cambridge Manuals in Archaeology, Cambridge University Press, Cambridge.

REYES, O. y C. MÉNDEZ 2010. Precisando la cronología para la inhumación tipo chenque, valle del río Cisnes (Aisén, Chile), Patagonia Central. Magallania, 38(2):97-102.

REYES, O., C. MÉNDEZ, A. MALDONADO, H. VELÁSQUEZ, V. TREJO, M. CÁRDENAS y A. ABARZÚA 2009. Uso del espacio de cazadores recolectores y paleoambiente Holoceno en el valle del río Cisnes, región de Aisén, Chile. Magallania, 37(2):91-107.
REYES, O., C. MÉNDEZ, H. VELÁSQUEZ y V. TREJO 2006. Distribuciones espaciales y contextos arqueológicos de cazadores recolectores esteparios en Alto río Cisnes (XI Región de Aisén). Magallania, 34(2):75-90.

REYES, O., C. MÉNDEZ, V. TREJO y H. VELÁSQUEZ 2007.

El Chueco 1: un asentamiento multicomponente en la estepa occidental de Patagonia Central (11400 a 2700 años cal. AP., 44옹. Magallania, 35(1):61-74.

SERPLAC. 2005. Atlas de la Región de Aysén. Ministerio de Planificación y Cooperación, LOM Ediciones, Santiago.

STERN, C. 1999. Black obsidian from central-south Patagonia; chemical characteristics, sources and regional distribution of artifacts. En: Soplando en el viento... Actas de las Terceras Jornadas de Arqueología de la Patagonia, pp: 221-234. Universidad Nacional del Comahue e Instituto Nacional de Antropología y Pensamiento Latinoamericano, San Carlos de Bariloche y Buenos Aires.

STERN, C., J. GÓMEZ OTERO y J. B. BELARDI 2000. Características químicas, fuentes potenciales y distribución de diferentes tipos de obsidianas en la costa e interior del centro-norte de la provincia del Chubut, Argentina. Anales del Instituto de la Patagonia, Serie Ciencias Sociales 28:275-290.

TREJO, V. y H. VELÁSQUEZ 2011. Informe restos de fauna del sitio El Chueco 1 (CIS 042). En: Informe proyecto FONDECYT 1090027 año 2, compilado por Méndez C. y O. Reyes. Santiago, MS.

VELÁSQUEZ, H. y F. MENA 2006. Distribuciones óseas de ungulados en la Cueva Baño Nuevo 1 (XI Región, Chile): un primer acercamiento. Magallania, 34(2):91-106. 